\title{
Functional alterations by a subgroup of neonicotinoid pesticides in human dopaminergic neurons
}

\author{
Dominik Loser ${ }^{1,2,3}(\mathbb{D})$ Maria G. Hinojosa ${ }^{5}$ Jonathan Blum ${ }^{3}$. Jasmin Schaefer ${ }^{1,2} \cdot$ Markus Brüll $^{3} \cdot$ Ylva Johansson $^{5}$. \\ Ilinca Suciu ${ }^{3} \cdot$ Karin Grillberger ${ }^{6} \cdot$ Timm Danker $^{1,2}$. Clemens Möller ${ }^{4}$ Iain Gardner ${ }^{7} \cdot$ Gerhard F. Ecker $^{6}$. \\ Susanne H. Bennekou ${ }^{8} \cdot$ Anna Forsby $^{5} \cdot$ Udo Kraushaar $^{1} \cdot$ Marcel Leist $^{3}$
}

Received: 7 December 2020 / Accepted: 17 March 2021 / Published online: 29 March 2021

(c) The Author(s) 2021

\begin{abstract}
Neonicotinoid pesticides, originally developed to target the insect nervous system, have been reported to interact with human receptors and to activate rodent neurons. Therefore, we evaluated in how far these compounds may trigger signaling in human neurons, and thus, affect the human adult or developing nervous system. We used SH-SY5Y neuroblastoma cells as established model of nicotinic acetylcholine receptor (nAChR) signaling. In parallel, we profiled dopaminergic neurons, generated from LUHMES neuronal precursor cells, as novel system to study nAChR activation in human post-mitotic neurons. Changes of the free intracellular $\mathrm{Ca}^{2+}$ concentration $\left(\left[\mathrm{Ca}^{2+}\right]_{\mathrm{i}}\right)$ were used as readout, and key findings were confirmed by patch clamp recordings. Nicotine triggered typical neuronal signaling responses that were blocked by antagonists, such as tubocurarine and mecamylamine. Pharmacological approaches suggested a functional expression of $\alpha 7$ and non- $\alpha 7 \mathrm{nAChRs}$ on LUHMES cells. In this novel test system, the neonicotinoids acetamiprid, imidacloprid, clothianidin and thiacloprid, but not thiamethoxam and dinotefuran, triggered $\left[\mathrm{Ca}^{2+}\right]_{\mathrm{i}}$ signaling at $10-100 \mu \mathrm{M}$. Strong synergy of the active neonicotinoids (at low micromolar concentrations) with the $\alpha 7 \mathrm{nAChR}$-positive allosteric modulator PNU-120596 was observed in LUHMES and SH-SY5Y cells, and specific antagonists fully inhibited such signaling. To provide a third line of evidence for neonicotinoid signaling via $\mathrm{nAChR}$, we studied cross-desensitization: pretreatment of LUHMES and SH-SY5Y cells with active neonicotinoids (at $1-10 \mu \mathrm{M}$ ) blunted the signaling response of nicotine. The pesticides (at 3-30 $\mu \mathrm{M}$ ) also blunted the response to the non- $\alpha 7$ agonist ABT 594 in LUHMES cells. These data show that human neuronal cells are functionally affected by low micromolar concentrations of several neonicotinoids. An effect of such signals on nervous system development is a toxicological concern.
\end{abstract}

Keywords Live-cell calcium imaging $\cdot$ Neurotoxicity $\cdot$ Nicotine $\cdot$ Desensitization $\cdot$ Molecular docking

\section{Abbreviations \\ ACh Acetylcholine \\ Aceta Acetamiprid}

Udo Kraushaar and Marcel Leist contributed equally.

Marcel Leist

marcel.leist@uni-konstanz.de

1 NMI Natural and Medical Sciences Institute at the University of Tübingen, 72770 Reutlingen, Germany

2 NMI TT GmbH, 72770 Reutlingen, Germany

3 In Vitro Toxicology and Biomedicine, Department Inaugurated by the Doerenkamp-Zbinden Foundation, University of Konstanz, Universitaetsstr. 10, 78457 Konstanz, Germany

4 Life Sciences Faculty, Albstadt-Sigmaringen University, 72488 Sigmaringen, Germany
ARfD Acute reference dose

AR-R AR-R 17779

AUC Area under the curve

BMC Benchmark concentration

$\left[\mathrm{Ca}^{2+}\right]_{\mathrm{i}}$ Intracellular free calcium concentration

5 Department of Biochemistry and Biophysics, Stockholm University, 10691 Stockholm, Sweden

6 Department of Pharmaceutical Sciences, University of Vienna, Vienna, Austria

7 CERTARA UK Limited, Simcyp Division, Level 2-Acero, 1 Concourse Way, Sheffield S1 2BJ, UK

8 Technical University of Denmark, Kongens Lyngby, Denmark 


\begin{tabular}{|c|c|}
\hline cAMP & $\begin{array}{l}\text { N6,2'-0-dibutyryl 3',5'-cyclic adenosine } \\
\text { monophosphate }\end{array}$ \\
\hline Cloth & Clothianidin \\
\hline Dino & Dinotefuran \\
\hline DMSO & Dimethyl sulfoxide \\
\hline Imida & Imidacloprid \\
\hline $\mathrm{Mec}$ & Mecamylamine \\
\hline MLA & Methyllycaconitine \\
\hline $\mathrm{nAChR}$ & Nicotinic acetylcholine receptor \\
\hline $\mathrm{pEC}_{25}$ & $\begin{array}{l}\text { Negative logarithm of the quarter maximal } \\
\text { effective concentration }\end{array}$ \\
\hline $\mathrm{pEC}_{50}$ & $\begin{array}{l}\text { Negative logarithm of the half-maximal effec- } \\
\text { tive concentration }\end{array}$ \\
\hline $\mathrm{pIC}_{50}$ & $\begin{array}{l}\text { Negative logarithm of the half-maximal inhibi- } \\
\text { tory concentration }\end{array}$ \\
\hline PBTK & Physiology-based toxicokinetic \\
\hline PLO & Poly-L-ornithine \\
\hline PNU & PNU-120596 \\
\hline Thiac & Thiacloprid \\
\hline Thiam & Thiamethoxam \\
\hline Tubo & Tubocurarine \\
\hline VTD & Veratridine \\
\hline
\end{tabular}

\section{Introduction}

Neonicotinoids are a class of insecticides that trigger nervous system disturbances by activation of the nicotinic acetylcholine (ACh) receptor (nAChR) (Brown et al. 2006; Tan et al. 2007). The compounds are widely used in agriculture for pest control (Jeschke et al. 2011; Goulson 2013; Casida and Durkin 2013), and they have been optimized to display a high species specificity. In general, they show a high potency on insect receptors, while they have been designed for low affinities on mammalian receptors (Tomizawa et al. 2000; Tomizawa and Casida 2003, 2005; Casida 2018). In regulatory studies, they have been proven to be relatively well-tolerated by rats, but some studies indicate an impact of neonicotinoids on mammals (Abou-Donia et al. 2008; Duzguner and Erdogan 2012; Gibbons et al. 2015; Burke et al. 2018; Berheim et al. 2019; Thompson et al. 2020).

Some doubts on the extent of the species selectivity have been raised by experiments on neonatal rat neurons, where acetamiprid and imidacloprid triggered signaling effects at concentrations as low as $1-10 \mu \mathrm{M}$ (Kimura-Kuroda et al. 2012). As nicotine signaling can affect the development of the mammalian nervous system as typical developmental neurotoxicant (Levin et al. 1993; LeSage et al. 2006; Aschner et al. 2017), concerns have been voiced that exposure of humans to neonicotinoids may bear the risk of developmental neurotoxicity (DNT). Clarification of neonicotinoid signaling in human neurons is, therefore, of high toxicological interest (EFSA Panel on Plant Protection Products and their Residues (PPR) 2013).

The endogenous neurotransmitter ACh affects neuronal activity via the activation of (so-called muscarinic) metabotropic receptors (mAChR) and (so-called nicotinic) ionotropic nAChR. The latter are a class of homo- or heteromeric ligand-gated channels with variable permeability for $\mathrm{Na}^{+}$and/or $\mathrm{Ca}^{2+}$ (Fucile 2004). Their activation leads to cell depolarization, to the activation of voltage-dependent $\mathrm{Ca}^{2+}$ channels, and thus, to an increase of the intracellular free $\mathrm{Ca}^{2+}$ concentration $\left(\left[\mathrm{Ca}^{2+}\right]_{\mathrm{i}}\right)$. A large number of genes coding for subunits of nAChRs have been identified, and all functional receptors are pentamers formed from either a single subunit (e.g., $\alpha 7$ ), two subunits (e.g., $\alpha 4$ and $\beta 2$ ) or $>2$ subunits. The subunit composition determines the ligand affinities and the gating properties (Nelson et al. 2003; Mihalak et al. 2006; Jonsson et al. 2006; Carbone et al. 2009; Capelli et al. 2011). For instance, $\alpha 7$ receptors exhibit fast inactivating kinetics (Elliott et al. 1996; Mihalak et al. 2006; Alijevic et al. 2020), while, e.g., $\beta 2$-containing receptors show slower inactivation properties (Elliott et al. 1996; Nelson et al. 2003; Mihalak et al. 2006; Alijevic et al. 2020). Both types of receptors are expressed in the central nervous system. E.g., nAChRs are expressed on dopaminergic neurons, where they regulate the release of dopamine (Rapier et al. 1988; Grady et al. 1992; Quik and Kulak 2002; Mameli-Engvall et al. 2006; Quik and Wonnacott 2011; de Kloet et al. 2015).

Substances that alter neurotransmitter signaling transiently (while they are present) in the adult nervous system may have long-term consequences (even for years after their actual exposure) in the developing nervous system (Slikker Jr et al. 2005; Grandjean and Landrigan 2006, 2014; Smirnova et al. 2014). This is not only due to the oftencited high vulnerability of the developing brain (Rice and Barone Jr 2000; Fritsche et al. 2018), but rather related to the fact that neurotransmitter signaling takes different roles in the developing and adult nervous system (Nguyen et al. 2001). While the brain is formed, GABA does not only serve short-term communication, but it also triggers synaptogenesis (Oh et al. 2016), synapse pruning (Wu et al. 2012), neuronal migration ( $\mathrm{Li}$ et al. 2018), stem cell fate (Song et al. 2012) and neurogenesis (Kriegstein 2005; Tozuka et al. 2005). Other neurotransmitters take similar roles, such as spine growth triggered by glutamate (Kwon and Sabatini 2011), and various neurogenic processes affected by serotonin (Schaefer et al. 2013; Migliarini et al. 2013; Agrawal et al. 2019), or nicotine (Slikker Jr et al. 2005; Dwyer et al. 2009; Slotkin et al. 2016; Zahedi et al. 2019). The toxicological consequence is that disturbance of neurotransmitter signaling during development can result in an altered brain connectivity in later life. Therefore, compounds showing acute interferences with adult neurotransmission need to 
be considered as potential developmental neurotoxicants (Grandjean and Landrigan 2006, 2014; Smirnova et al. 2014).

Hundreds of signaling molecules and alterations in the nervous system converge to very few cellular changes, such as alterations of the neuronal membrane potential and modulation of ion channels. A traditional method to assess this is to pre-load cells with radioactive ${ }^{86} \mathrm{Rb}^{+}$and to quantify the efflux upon stimulation. Using this method, SH-SY5Y neuroblastoma cells have been established as model to study nAChR signaling (Lukas et al. 1993; Tomizawa and Casida 1999). Cell membrane depolarization activates voltagedependent $\mathrm{Ca}^{2+}$ channels, leading to a transient increase of the $\left[\mathrm{Ca}^{2+}\right]_{\mathrm{i}}$, and some nAChRs in neurons are directly permeable for $\mathrm{Ca}^{2+}$ (reviewed by Fucile 2004). Therefore, $\mathrm{Ca}^{2+}$-imaging can be used to capture many different types of signaling events. The detection can be performed at high throughput using live-cell fluorescence imaging of neuronal cultures loaded with calcium-sensitive dyes (Leist and Nicotera 1998; Sirenko et al. 2019; Grunwald et al. 2019; Karreman et al. 2020; Brüll et al. 2020). A more direct, but lower throughput method to assess the neuronal membrane potential is patch clamp electrophysiology. This approach can directly measure the voltage or the current flow over neuronal membranes (Smith et al. 1992; Kang and Kitai 1993; Molleman 2003; Cummins et al. 2009).

The neuronal precursor cell line LUHMES is a widely used model to study biochemical and pharmacological effects on the human nervous system, as well as various types of toxicities (Krug et al. 2013, 2014; Zhang et al. 2014; Lohren et al. 2015; Smirnova et al. 2016; Harris et al. 2017; Tong et al. 2017; Witt et al. 2017; Delp et al. 2018a, b, 2019, 2021; Brüll et al. 2020). The cells can be differentiated into post-mitotic dopaminergic neurons (Scholz et al. 2011), and we have recently shown their usefulness for functional neurotoxicity assessment, including the measurement of effects on ionotropic (purinergic) receptors (Loser et al. 2021). The SH-SY5Y neuroblastoma cells are another human model, which has been used for studies on $\mathrm{Ca}^{2+}$ signaling in neuronal function such as $\mathrm{mAChR}$ and voltage-dependent $\mathrm{Ca}^{2+}$ channel activation (Gustafsson et al. 2010). The cells express several nAChR subunits (Gould et al. 1992; Peng et al. 1994) and nAChRs have been the target for neurotoxicity studies (Ring et al. 2015) and investigations on the role in amyloid processing (Mousavi and Hellström-Lindahl 2009) using the SH-SY5Y cell model.

Here, we characterized functional nAChRs on LUHMES neurons, and we asked whether SH-SY5Y and LUHMES cell cultures can be utilized for the assessment of xenobiotic effects on nAChRs. After confirming that the test systems indeed delivers robust and literature-congruent data on nicotinic signaling, we evaluated the six neonicotinoids with the highest market share (Jeschke et al. 2011; Bass et al. 2015), namely acetamiprid (Aceta), imidacloprid (Imida), clothianidin (Cloth), thiacloprid (Thiac), thiamethoxam (Thiam) and dinotefuran (Dino). Our studies' overall goal was to identify potential modulatory effects of these pesticides on human neuronal $\left[\mathrm{Ca}^{2+}\right]_{\mathrm{i}}$ homeostasis. As it is known that disturbed cholinergic signaling, e.g., by exposure to nicotine, may trigger developmental neurotoxicity, the underlying rationale for this study was to evaluate the propensity for neonicotinoids to replicate nicotine toxicity in preterm or neonate infants.

\section{Materials and methods}

\section{Materials and chemicals}

An overview of experimental tool compounds and toxicants is given in table S1. Chemical structures of acetylcholine (https://pubchem.ncbi.nlm.nih.gov/compound/187\#section= 2D-Structure), cytisine (https://pubchem.ncbi.nlm.nih.gov/ compound/10235\#section=2D-Structure), nicotine (https:// pubchem.ncbi.nlm.nih.gov/compound/89594\#section= 2D-Structure) and varenicline (https://pubchem.ncbi.nlm. nih.gov/compound/170361\#section=2D-Structure) were obtained from PubChem and visualized in ChemDraw JS (version 19.0.0-CDJS-19.0.x.9+ da9bec968, PerkinElmer).

\section{LUHMES cell culture}

The cultivation of the LUHMES cells was performed as described earlier (Scholz et al. 2011; Krug et al. 2013; Schildknecht et al. 2013). In brief, LUHMES cells were cultured in standard cell culture flasks (Sarstedt) that were pre-coated with $50 \mu \mathrm{g} / \mathrm{ml}$ poly-L-ornithine (PLO) and $1 \mu \mathrm{g} /$ $\mathrm{ml}$ fibronectin (Sigma-Aldrich) in $\mathrm{H}_{2} \mathrm{O}$ overnight at $37^{\circ} \mathrm{C}$. The cells were maintained in proliferation medium containing advanced DMEM/F12 (Gibco) with $2 \mathrm{mM}$ L-glutamine (Sigma-Aldrich), $1 \times \mathrm{N} 2$-supplement (Gibco) and $40 \mathrm{ng} / \mathrm{ml}$ recombinant human basic fibroblast growth factor (FGF-2, $\mathrm{R} \& \mathrm{D}$ Systems). The cells were kept at $37^{\circ} \mathrm{C}$ and $5 \% \mathrm{CO}_{2}$ and passaged three times a week, when the culture reached a confluency of $75-90 \%$. Cells were used until passage 18 . For differentiation, cells were cultured in differentiation medium consisting of advanced DMEM/F12 (Gibco) supplemented with $2 \mathrm{mM}$ L-glutamine (Sigma-Aldrich), $1 \times \mathrm{N} 2$-supplement (Gibco), 1 mM N6,2'-0-dibutyryl 3',5'-cyclic adenosine monophosphate (cAMP) (Sigma-Aldrich), $1 \mu \mathrm{g} / \mathrm{ml}$ tetracycline (Sigma-Aldrich) and $2 \mathrm{ng} / \mathrm{ml}$ recombinant human glial cell-derived neurotrophic factor (GDNF, R\&D Systems).

For $\mathrm{Ca}^{2+}$-imaging, the cells were pre-differentiated for $48 \mathrm{~h}$ in cell culture flasks, detached and plated at a density of 20,000 cells and 30,000 cells per well on $0.1 \%$ 
PEI-coated 384-well and 96-well plates (Greiner BioOne), respectively. For manual patch clamp recordings, the cells were plated at a density of 750 cells $/ \mu 1$ on $0.1 \%$ PEI-coated glass coverslips. The cells were further differentiated for another 7-8 days. 50\% of the medium was exchanged every $2-3$ days.

\section{Cell culture of SH-SY5Y cells}

SH-SY5Y cells (passage 50-70) were cultured as previously described (Attoff et al. 2016) and monthly screened for mycoplasma contamination (Lonza MycoAlert Mycoplasma Detection Kit). Briefly, they were cultured in MEM supplemented with $10 \%$ fetal bovine serum (Gibco, 31330095), 1\% non-essential amino acid solution (Gibco, 11140035), 2 mM L-glutamine (Gibco, 25030024), $100 \mu \mathrm{g} / \mathrm{ml}$ streptomycin and $100 \mathrm{U} / \mathrm{ml}$ penicillin (Gibco, 15140122). For maintenance culture, SH-SY5Y cells were seeded at 27,000 cells $/ \mathrm{cm}^{2}$ in $75 \mathrm{~cm}^{2}$ cell culture flasks (Corning). The cells were passaged once a week using TrypLE Express Enzyme (Gibco). SH-SY5Y cells were differentiated into a neuronal-like phenotype by exchanging the maintenance medium with differentiation medium consisting of DMEM/F12 (Gibco, 31330095) supplemented with $1 \mathrm{mM}$ L-glutamine (Gibco, 25030024), $100 \mu \mathrm{g}$ streptomy$\mathrm{cin} / \mathrm{ml}, 100 \mathrm{U}$ penicillin/ml, $1 \times \mathrm{N} 2$-supplement (Gibco, 17502048) and $1 \mu \mathrm{M}$ all-trans retinoic acid (RA, Sigma, R2625) $24 \mathrm{~h}$ after seeding. The cells were incubated in $100 \%$ humidity at $37{ }^{\circ} \mathrm{C}$ in air with $5 \% \mathrm{CO}_{2}$.

For determination of cell viability, 35,000 SH-SY5Y cells/well $\left(109,375 \mathrm{cells} / \mathrm{cm}^{2}\right)$ were seeded in maintenance culture medium in clear 96-well plates (Corning, 3599). $24 \mathrm{~h}$ after seeding, maintenance medium was replaced with differentiation medium and incubated for 3 days before exposure with compounds. Cell viability was determined after 24-h exposure with nicotine or neonicotinoids by the conversion of resazurin (Sigma, R2625) to resorufin in metabolically active cells (O'Brien et al. 2000). A $20 \times$ resazurin stock solution was prepared by dissolving $11 \mathrm{mg}$ resazurin salt in $1 \mathrm{ml} 0.1 \mathrm{M} \mathrm{NaOH}$ and adjusting to $50 \mathrm{ml}$ with $\mathrm{PBS}^{-1-}$ (pH set to 7.8 with $0.1 \mathrm{M} \mathrm{HCl}$ ). The $20 \times$ resazurin stock solution was sterile filtered and stored at $4{ }^{\circ} \mathrm{C}$ protected from light. After exposure with compounds, $150 \mu \mathrm{l}$ medium was removed leaving $50 \mu \mathrm{l}$ in each well and subsequently, $50 \mu \mathrm{l}$ of $2 \times$ resazurin solution dissolved in DMEM/F12 was added. The plate was incubated for $3 \mathrm{~h}$ at $37{ }^{\circ} \mathrm{C}$ with $5 \% \mathrm{CO}_{2}$. Resorufin fluorescence was measured at excitation $540 \mathrm{~nm}$ and at emission $590 \mathrm{~nm}$ using a FlexStation II fluorometer (Molecular Devices).

\section{Gene expression profiling}

Five biological replicates were generated from LUHMES cells differentiated for 2, 3, 5, 6, 8, 10, and 11 days, as well as from undifferentiated LUHMES cells (day 0). Samples were analyzed via the TempO-Seq assay, which is a targeted RNA-sequencing method developed by BioSpyder Technologies Inc. (Carlsbad, CA, USA). The method is described in detail in House et al. (2017). For sample preparation, LUHMES grown in 96-well plates were lysed in $25 \mu \mathrm{l} 1 \times$ BioSpyder lysis buffer according to the manufacturer's instructions. The lysate from 10 wells was pooled for each sample. Samples were stored at $-80^{\circ} \mathrm{C}$ before shipping on dry ice to BioClavis (BioClavis, ltd., Glasgow, UK) for TempO-Seq analysis. The resulting FASTQ files were aligned using the STAR algorithm to a pseudo-transcriptome by BioClavis and eventually normalized and standardized to a data format of $\mathrm{x}$ gene specific counts per 1 million reads. Traditional whole-genome RNA-sequencing (RNAseq) was performed for comparison and validation. Cells were cultured in 6-well plates. For sample preparation, medium was removed and cells were lysed in TriFast reagent (Peqlab, VWR, USA). The lysate of six wells was pooled for each sample. Samples were stored at $-20^{\circ} \mathrm{C}$ until they were sent on dry ice to the department of toxicogenomics at the University Maastricht, Netherlands, for RNAseq analysis.

Changes in SH-SY5Y nAChR subunit mRNA expression after exposure with nicotine or neonicotinoids were analyzed by whole-genome TempO-Seq by BioClavis (BioClavis, ltd., Glasgow, UK) as described for the LUHMES cells. Cells (35,000 cells/well) were plated in 96-well plates (Corning) and differentiated for 3 days as described above. After 6 and $24 \mathrm{~h}$ of exposure with nicotine and neonicotinoids, $50 \mu \mathrm{l}$ lysis buffer (BioClavis) was added per well according to the manufacturer's instructions, and the plates were stored at $-80{ }^{\circ} \mathrm{C}$. Before shipment, the plates were thawed on ice and two identical samples/situations were pooled to give $100 \mu \mathrm{l}$ in one well in a new 96-well plate kept on ice. The plate with pooled samples was stored at $-80{ }^{\circ} \mathrm{C}$ until shipment for TempO-Seq analysis.

The time course of expression in control cells was analyzed by RNA-sequencing. For this, SH-SY5Y cells were sampled at $0,3,6$, and 9 days of differentiation. The mRNA extraction and RNA-sequencing experimental setup including data analysis has been described in Attoff et al. (2020).

\section{Neurite outgrowth assay}

LUHMES cells were differentiated for 2 days in differentiation medium in PLO-fibronectin pre-coated cell culture flasks. On day 2 of differentiation ( $\mathrm{d} 2$ neurons), cells were seeded at a density of $100,000 \mathrm{cells} / \mathrm{cm}^{2}$ into PLO-fibronectin pre-coated 96-well plates. After $1 \mathrm{~h}$ of attachment, cells 
were treated for $24 \mathrm{~h}$ with nicotine and neonicotinoids spanning a concentration range of $5 \mathrm{nM}-100 \mu \mathrm{M}$. Cells were stained with H-33342 $(1 \mu \mathrm{g} / \mathrm{ml})$ and calcein-AM $(1 \mu \mathrm{M})$ and high-content imaging was performed. Live cells and neurite area were assessed in parallel using an automated algorithm as described previously (Stiegler et al. 2011; Krug et al. 2013).

\section{LUHMES Ca ${ }^{2+}$-imaging}

$\mathrm{Ca}^{2+}$-imaging was performed using HT Functional DrugScreening System FDSS/ $\mu$ CELL (Hamamatsu Photonics) at nominal $37^{\circ} \mathrm{C}$. The FDSS/ $\mu$ Cell system enables the indirect recording of changes of $\left[\mathrm{Ca}^{2+}\right]_{i}$ via a $\mathrm{Ca}^{2+}$-sensitive fluorescent dye. The fluorescence signal of a complete 384-well plate is acquired at once with a high-speed and high-sensitivity digital ImagEM X2 EM-CCD camera (Electron Multiplying Charge-Coupled Device, Hamamatsu Photonics), but with limited spatial resolution. Therefore, the software only determines the mean fluorescence signal of each well rather than of individual cells. For compound application, the integrated dispenser head with 384 pipette tips was used, which can add the test compound to all wells simultaneously. Cells were preincubated with Cal-520 AM (AAT Bioquest) at a concentration of $1 \mu \mathrm{M}$ for $1 \mathrm{~h}$ at $37^{\circ} \mathrm{C}$. For recording, the medium was exchanged by a buffer solution containing $[\mathrm{mM}]: 135 \mathrm{NaCl}, 5 \mathrm{KCl}, 0.2 \mathrm{MgCl}_{2}, 2.5 \mathrm{CaCl}_{2}, 10$ HEPES and 10 D-glucose, $\mathrm{pH}$ 7.4. Test compound application was executed after obtaining a $1.5 \mathrm{~min}$ baseline recording. Where applicable, a second application was executed $4.5 \mathrm{~min}$ after the first application. The total recording never exceeded 8 min.

For $\mathrm{Ca}^{2+}$-imaging experiments with a higher resolution on the single-cell level, the Cell Observer (Carl Zeiss Microscopy, GER) was used. The $\mathrm{Ca}^{2+}$-sensitive dye, the cell handling before the experiment and the buffer were the same as described above for the experiments with the highthroughput FDSS/ $\mu$ CELL system. The compounds were applied after an initial baseline recording of the fluorescence intensity of at least $10 \mathrm{~s}$.

\section{$\mathrm{Ca}^{2+}$ measurements in SH-SY5Y}

To measure acute changes in the average $\left[\mathrm{Ca}^{2+}\right]_{\mathrm{i}}$ of a population, SH-SY5Y cells were examined in the 96-well plate fluorescence reader FlexStation II (Molecular Devices) using the fluorophore Fura-2AM. SH-SY5Y (35,000 cells/ well; 109,375 cells $/ \mathrm{cm}^{2}$ ) were seeded in maintenance culture medium in black 96-well plates with clear bottom (Corning, \#3603). $24 \mathrm{~h}$ after seeding, maintenance medium was replaced with differentiation medium. After $72 \mathrm{~h}$ of differentiation, Fura-2AM diluted in KRH buffer $(125 \mathrm{mM}$ $\mathrm{NaCl}, 5 \mathrm{mM} \mathrm{KCl}, 1.2 \mathrm{mM} \mathrm{MgSO}$, $1.2 \mathrm{mM} \mathrm{KH}_{2} \mathrm{PO}_{4}$,
$2.0 \mathrm{mM} \mathrm{CaCl}_{2}, 6.0 \mathrm{mM}$ D-glucose, and $25 \mathrm{mM}$ HEPES (free acid), $\mathrm{pH}$ adjusted to 7.4 by $1.0 \mathrm{M} \mathrm{NaOH}$ ) was added to the medium to a final concentration of $4 \mu \mathrm{M}$ (Gustafsson et al. 2010). The plates were incubated for $30 \mathrm{~min}$ at $37^{\circ} \mathrm{C}$, before cells were washed once with $200 \mu \mathrm{KRH}$ buffer. $90 \mu \mathrm{l}$ of KRH buffer without or with $10 \mu \mathrm{M}$ PNU $\pm 125 \mu \mathrm{M}$ mecamylamine (Mec) was added to the Fura-2AM-loaded cells. The plate was again incubated for 20 min to allow full hydrolysis of the AM group before the experiment. The fluorescence was assessed at $37{ }^{\circ} \mathrm{C}$ in the fluorescence plate reader (FlexStation II; Molecular Devices) at two different excitation wavelengths, $340 \mathrm{~nm}$ for $\mathrm{Ca}^{2+}$-bound Fura-2 and $380 \mathrm{~nm}$ for free Fura-2, and at $510 \mathrm{~nm}$ emission every $3.1 \mathrm{~s}$ using bottom read settings. After 26-29 s of initial baseline recording of the fluorescence intensity, $10 \mu \mathrm{l}$ of the compound dilution (10 times higher than the final concentration to the cells) was transferred automatically by the FlexStation II ("Flex mode"), column wise to the cell plate wells (five wells per concentration) and the fluorescence intensity was monitored for another $150 \mathrm{~s}$. The ratio of fluorescence intensity at $340 / 380 \mathrm{~nm}$ was determined and the mean values from the baseline recording before addition of test compounds was set to zero. The acute change in the $\mathrm{Ca}^{2+}$ influx after addition of the compounds was quantified as the area under the curve using the SoftMax Pro 4.8 software (Molecular Devices). All test compounds were dissolved in DMSO and stored as $100 \mathrm{mM}$ stock solutions at $-20^{\circ} \mathrm{C}$. At the day of experiments, compounds were diluted in $\mathrm{KRH}$ buffer in 1:3 series, with $100 \mu \mathrm{M}$ as the highest concentration. The DMSO concentration was kept to $0.1 \%$ in all dilution steps and 0.1\% DMSO in KRH buffer was also used as a negative control. $\mathrm{KCl}(30 \mathrm{mM})$ in $\mathrm{KRH}$ was used as a positive control. To check the implication of the $\alpha 7 \mathrm{nAChR}$ isoform in the cholinergic response, the $\alpha 7 \mathrm{nAChR}$ allosteric modulator PNU $(10 \mu \mathrm{M})$ was used to evaluate the effect on $\mathrm{Ca}^{2+}$ influx triggered by nicotine and the six neonicotinoids. For desensitization studies, the cells were pre-exposed for 20 min with Thiam, Dino or Thiac (final concentration range $0.046-100 \mu \mathrm{M})$ together with $10 \mu \mathrm{M}$ PNU before addition of $11 \mu \mathrm{M}$ nicotine. The nicotine-induced $\mathrm{Ca}^{2+}$ influx was normalized to the $\mathrm{Ca}^{2+}$ response triggered by $30 \mathrm{mM} \mathrm{KCl}$. The $\mathrm{Ca}^{2+}$ influx induced by the neonicotinoids was normalized to the response to $11 \mu \mathrm{M}$ nicotine.

\section{Manual patch clamp recordings}

Manual patch clamp experiments were performed in the whole-cell mode (Hamill et al. 1981) with an EPC 10 USB patch clamp amplifier and PatchMaster Software (version $2 \times 90.5$; HEKA Elektronik, Lambrecht, Germany). Extracellular solution contained $[\mathrm{mM}]: 140 \mathrm{NaCl}, 4 \mathrm{KCl}$, $1 \mathrm{MgCl}_{2}, 1.8 \mathrm{CaCl}_{2}, 10$ HEPES and 10 D-glucose, $\mathrm{pH}$ 7.4. Intracellular solution contained [mM]: $107 \mathrm{~K}$-gluconate, 
$10 \mathrm{KCl}, 1 \mathrm{MgCl}_{2}$, 10 HEPES, 5 EGTA, $4 \mathrm{Na}_{2} \mathrm{ATP}$ and 0.2 NaGTP, pH 7.2. Recordings were executed at room temperature. For agonist tests in current-clamp and voltage-clamp mode, cells were kept at a holding potential of $-70 \mathrm{mV}$ and the compounds were applied for $5 \mathrm{~s}$.

\section{Physicochemical properties and molecular docking studies}

Based on the specific ChEMBL-ID of the substances, AlogP values as a descriptor for lipophilicity were extracted from the ChEMBL-database (https://www.ebi.ac.uk/chembl) (Davies et al. 2015; Mendez et al. 2019). The values provided by ChEMBL were calculated using RDKit (https:// www.rdkit.org, 2018) based on the method described by Wildman and Crippen (Wildman and Crippen 1999). Polar surface areas (PSA values) were calculated using the maestro 2020-2 software (Schrödinger Release 2020-2 2020) suite (Ertl et al. 2000).

The cryo-EM-resolved 3D-structures for the human nAChR $\alpha 4 \beta 2$-subtype were extracted from the protein data bank (rcsb.org (Berman et al. 2000)). Structure PDBID: $6 \mathrm{cnj}$ was used for the $\alpha 4 \beta 2$-binding site because of its superior resolution compared to structure $6 \mathrm{cnk}$ which was used for the $\alpha 4 \alpha 4$-binding site (Walsh et al. 2018). For the $\alpha 4 \beta 2$-isoform, the box center of the grid for the induced fit docking (IFD) run was chosen to be the centroid of the cocrystallized ligand nicotine between chain A and B: [A:402] in $6 \mathrm{cnj}$ and [A:405] in 6cnk (Walsh et al. 2018), respectively.

The structure of the human nAChR $\alpha 7$-isoform has not been experimentally resolved yet, but there are published homology models of the ligand-binding domain (LBD) available that were used for docking studies on this subtype (Ng et al. 2018). A recent paper from 2020 provided the information for the 3D-structure of this constructed extracellular LBD, that consists of two chains of the protein (Sakkiah et al. 2020). Previous studies characterized key ligand-binding residues on the human $\mathrm{nAChR} \alpha 7$-subtype as follows (Ng et al. 2018; Sakkiah et al. 2020): Tyr32, Phe33, Ser34, Trp55, Leu56, Gln57, Met58, Ser59, Trp60, Thr77, Arg79, Trp107, Val108, Leu109, Val110, Asn111, His115, Cys116, Gln117, Tyr118, Leu119, Pro120, and Pro121 from the complementary subunit, and Ser148, Trp149, Ser150, Tyr151, Gly152, Arg186, Phe187, Tyr188, Cys190, Cys 191, Lys192, Glu193, Pro194, and Tyr195 from the principal subunit. Therefore, the centroid of these amino acids around the $\alpha 7$-binding site was used as center of the grid for docking studies on this isoform.

Both, proteins and ligands have been prepared prior to the IFD protocol with extended sampling at $\mathrm{pH} 7 \pm 0.5$ using LigPrep and Protein preparation Wizard with default settings and an OPLS3e force field (Harder et al. 2016) that allowed the binding grid to adapt the residues around the ligand poses within $5 \AA$. The box size was set to $12 \AA$ in Maestro (Schrödinger Release 2020-2 2020).

An induced fit docking protocol as implemented in the Schrödinger Software Suite was applied. The protocol comprises a Glide initial docking run where the ligands are docked to the previously defined grid rigidly after a constrained minimization (Prime) of the receptor has been performed (Sherman et al. 2006; Schrödinger Release 2020-2 2020). A large number of poses per ligand was generated by this first docking run, from which only a set was passed on to the next steps by applying energy filters (Sherman et al. 2006; Schrödinger Release 2020-2 2020). This was followed by Prime side-chain prediction, another Prime minimization, Glide redocking and eventually the Scoring State. The resulting poses were then used as input for interaction fingerprint clustering with the average linking method (Schrödinger Release 2020-2 2020).

\section{Data analysis and statistics}

For the high-throughput $\mathrm{Ca}^{2+}$-imaging data obtained in LUHMES cells, an offset correction using the FDSS software (version 3.2) was performed. Afterwards, the data were exported and further analyzed with scripts written in R (version 3.6.3) (R Core Team 2020). The concentration-response curves were fitted using a log-logistic model described by Ritz et al. (2015), utilizing the R package $d r c$ with its function $\operatorname{drm}()$ and $L L 2.2()$ with the following equation: $f(x)=d l$ $[1+\exp (b(\log (x)-\tilde{e}))]$ (Ritz et al. 2015). The logarithm of the half-maximal effective concentration $\left(\operatorname{logEC_{50}}\right)$ between 0 and the upper limit $(d)$, which was set to 1 is represented by $\tilde{e}, x$ denotes the concentration and $b$ stands for the slope parameter (Ritz et al. 2015). In cases with normalizations to responses induced by other compounds, the function $L L 2.3($ ) was used with a variable upper limit ( $d$; Ritz et al. 2015). The same equation was used to determine the half-maximal inhibitory concentration $\left(\log \mathrm{IC}_{50}\right)$. Then, the $\log \mathrm{EC}_{50}$ and $\log \mathrm{IC}_{50}$ values were converted into the $\mathrm{pIC}_{50}$ and $\mathrm{pEC}_{50}$ values, which are the negative logarithms to base 10 .

The single-cell $\mathrm{Ca}^{2+}$-imaging recordings were exported and analyzed in Fiji ImageJ (version 1.52i) to get the average fluorescence signal of each cell. These signals were further analyzed in R, where a threshold detection was performed to detect responding cells. For this, the offset was corrected by subtracting the mean of $20-65 \%$ of the fluorescence signal of the pre-application period from the recording, to be robust against spontaneous activity. The threshold was defined as mean $+3 \times \mathrm{SD}$ of the negative control recordings, during the detection phase of $6.5 \mathrm{~s}$.

The raw data of the manual patch clamp recordings were analyzed in scripts written in R. For leak subtraction, the $\mathrm{P} / 4$ algorithms of PatchMaster were used in voltageclamp recordings. The following $\mathrm{R}$ packages were utilized 
for data handling: cowplot (Wilke 2019), dplyr (Wickham et al. 2020), drc (Ritz et al. 2015), ephys2 (Danker 2018), ggplot2 (Wickham 2016), htmlwidgets (Vaidyanathan et al. 2019), lemon (Edwards 2019), magick (Ooms 2020), magrittr (Bache and Wickham 2014), matrixStats (Bengtsson 2020), miniUI (Cheng 2018), modelr (Wickham 2020), multcomp (Hothorn et al. 2008), plotrix (Lemon 2006), proto (Grothendieck et al. 2016), shiny (Chang et al. 2020), shinyjs (Attali 2020), shinyTree (Trestle Technology, LLC 2017), and tidyverse (Wickham et al. 2019).

Concentration-effect responses in the SH-SY5Y $\left[\mathrm{Ca}^{2+}\right]_{i}$ were analyzed by the GraphPad Prism8.0 software using the four-parameter sigmoidal curve fit settings and the concentrations giving $50 \%\left(\mathrm{BMC}_{50}\right)$ increase in $\left[\mathrm{Ca}^{2+}\right]_{\mathrm{i}}$ in relation to the nicotine response were estimated.

The raw count tables of gene expression profiling with TempO-Seq assay and traditional whole-genome RNAsequencing (RNAseq) were analyzed with the R package DESeq2 (v1.24.0) (Love et al. 2014). RNAseq counts were normalized to the library size and the transcript length [Transcripts per kilobase million (TPM)] (Wagner et al. 2012). TempoSeq counts were normalized to total counts per sample [counts per million (CPM)]. Gene lengths were retrieved from the hg18 reference genome (NCBI Build 36.1) with the R package Goseq (v1.40.0) (Young et al. 2010). TPM/CPM were averaged over the five biological replicates.

Unless mentioned differently, values are presented as mean \pm SEM. If not indicated otherwise, experiments were performed with at least three technical replicates per condition. Detailed data on $\mathrm{pEC}_{50}, \mathrm{pIC}_{50}$ and $\mathrm{n}$ numbers are found in supplementary tables. Unless mentioned differently, statistical significance was defined as $P<0.05$ and was determined by one-way ANOVA with Dunnett's post hoc test as indicated. To determine benchmark concentrations, and their upper and lower 95\% confidence intervals (BMCL, BMCU), the BMC online software of UKN was used (Krebs et al. 2020).

\section{Results and discussion}

\section{Suitability of LUHMES neurons to study human $n A C h R$ responses}

We used general gene expression profiling data to check the suitability of LUHMES as a model for an ACh signaling target cell. Two transcriptomics approaches based on RNA sequencing suggested that the cells express several subunits of the nAChR. Particularly high signals were obtained in differentiated cells for the $\alpha 4, \alpha 7$, and $\beta 2$ chains, but also some other cholinergic components showed gene expression. For instance, ACh esterase (AChE) and the muscarinic AChR4 were up-regulated during the differentiation process (Fig. S1). Our data support the hypothesis that multiple nAChR subtypes transmit neurotransmitter signals to LUHMES cells, but gene expression data alone do not reveal information about protein expression and function. Therefore, we investigated the effect of the selective nAChR agonist nicotine by performing measurements of the $\left[\mathrm{Ca}^{2+}\right]_{\mathrm{i}}$ as functional endpoint. Application of nicotine resulted in a rapid and concentration-dependent transient rise in $\left[\mathrm{Ca}^{2+}\right]_{\mathrm{i}}$ (Fig. 1a). A quantification of the nicotine signaling yielded a $\mathrm{pEC}_{50}$ value of 5.9 (Fig. 1b). This finding is in line with other published datasets on human nicotinic receptors determined by other techniques, confirming the applicability of $\mathrm{Ca}^{2+}$-imaging used here: e.g., $\mathrm{pEC}_{50}$ values of 5.5-6.1 $\left(\mathrm{EC}_{50}: 0.9-3.5 \mu \mathrm{M}\right)$ have been reported for human $\alpha 4 \beta 2$ nAChRs using patch clamp (Buisson et al. 1996; Wu et al. 2006; Chen et al. 2018), $\mathrm{Ca}^{2+}$-imaging (Chavez-Noriega et al. 2000; Capelli et al. 2011) and membrane potential fluorescence (Fitch et al. 2003). Patch clamp recordings with human $\alpha 6 / 3 \beta 2 \beta 3$ (Armstrong et al. 2017; Chen et al. 2018) or $\alpha 4 \beta 4$ (Wu et al. 2006) nAChRs showed $\mathrm{pEC}_{50}$ values of $\sim 5.9$. In this context, it is noteworthy that muscular (nonneuronal) nAChR $(\alpha 1 \beta 1 \delta \gamma / \varepsilon)$ have clearly lower nicotine affinities (Fitch et al. 2003; Capelli et al. 2011) of around $25 \mu \mathrm{M}\left(\mathrm{pEC}_{50}\right.$ : 4.6).

After these encouraging initial experiments on nicotinic signaling, we used cytisine as a second, well-established agonist. This compound exhibits high affinity and low efficacy for $\beta 2$-containing nAChRs (like $\alpha 4 \beta 2$ ) (Coe et al. 2005; Rollema and Hurst 2018). The compound-induced $\mathrm{Ca}^{2+}$-signals were comparable in both kinetics and sensitivity to nicotine (Fig. 1c). The potency of cytisine $\left(\mathrm{pEC}_{50}: 6.0\right)$ was also in the $1 \mu \mathrm{M}$ range. A similar set of data $\left(\mathrm{pEC}_{50}\right.$. 6.1) was obtained for a third nicotinic agonist, varenicline (Fig. 1b) (Mihalak et al. 2006). Again, these data were in good agreement with data obtained by several other functional test platforms (Chavez-Noriega et al. 2000; Fitch et al. 2003; Coe et al. 2005; Wu et al. 2006; Chatterjee et al. 2011; Arias et al. 2015).

As fourth agonist, we used the neurotransmitter ACh itself. The $\mathrm{pEC}_{50}$ of 6.0 (Fig. 1b) is in accordance with a large set of literature data on the signaling effects of this endogenous ligand (Buisson et al. 1996; Kuryatov et al. 1997; Nelson et al. 2003; Bermudez and Moroni 2006; Carbone et al. 2009; Mineur et al. 2009; Harpsøe et al. 2011; Benallegue et al. 2013; Armstrong et al. 2017). Finally, pilocarpine was used as mAChR agonist (Šantrůčková et al. 2014). Concentrations of up to $30 \mu \mathrm{M}$ (n $\geq 7$, data not shown) did not trigger any $\left[\mathrm{Ca}^{2+}\right]_{i}$ changes. In summary, the quantitative data on four diverse $\mathrm{nAChR}$ agonists (Fig. 1d) indicate a functional expression of neuronal nAChRs, and the suitability of LUHMES cells to study compounds affecting the nicotinic signaling. 

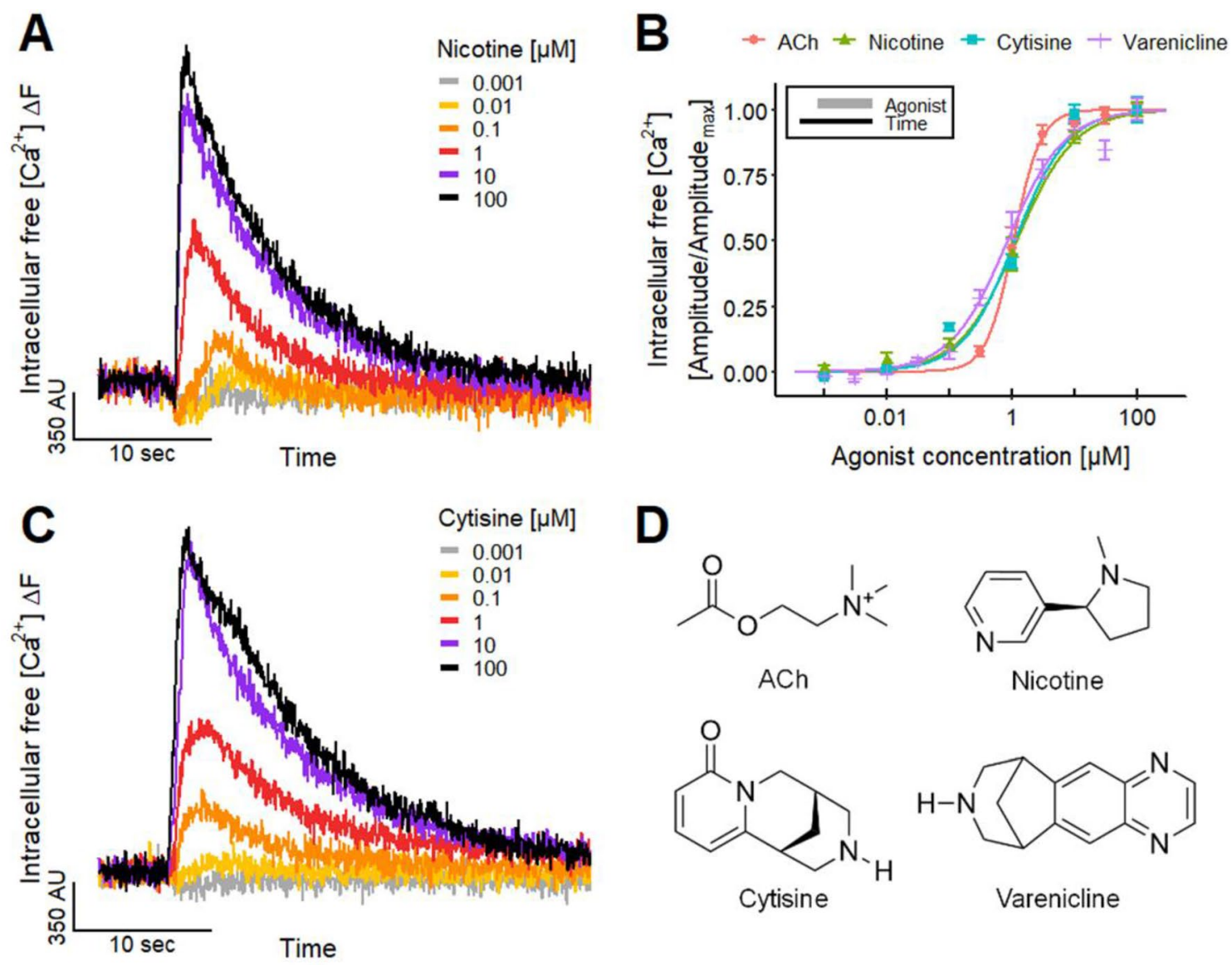<smiles>CC(=O)OCC[N+](C)(C)C</smiles><smiles>CN1CCC[C@H]1c1cccnc1</smiles><smiles>O=c1cccc2n1C[C@H]1C[C@H]2CN1</smiles><smiles>c1cnc2cc3c(cc2n1)C1CNCC3C1</smiles>
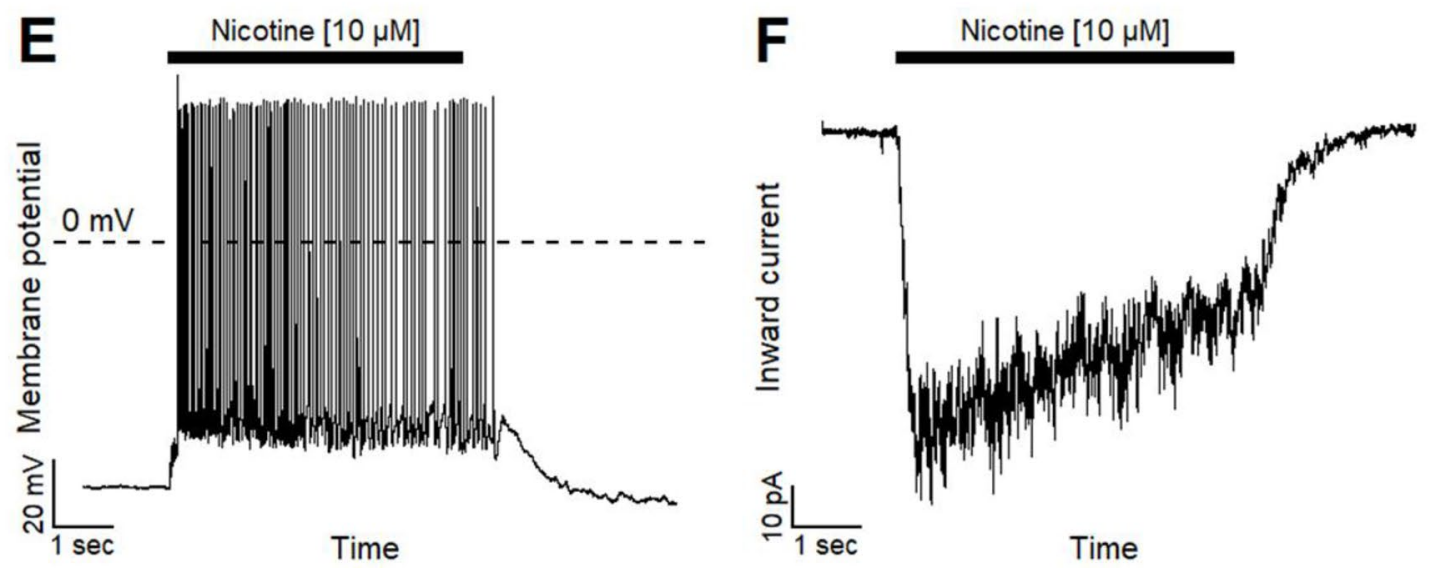

Fig. 1 Identification of functional nicotinic acetylcholine receptors (nAChRs) on LUHMES neurons. a Traces of $\mathrm{Ca}^{2+}$-imaging recordings show the concentration-dependent effects of the nAChR agonist nicotine on LUHMES neurons. b Concentration-response curves for the effects of nAChR agonists acetylcholine (ACh), nicotine, cytisine and varenicline with $\mathrm{pEC}_{50}$ values of $5.98 \pm 0.03,5.93 \pm 0.05$, $5.95 \pm 0.05$ and $6.08 \pm 0.04$, respectively. Note the treatment scheme (upper left corner), illustrating the experimental design. Detailed

To investigate the electrophysiological impact on LUHMES neurons, manual patch clamp recordings were performed. Application of nicotine $(10 \mu \mathrm{M})$ to a total of 42

data on $\mathrm{n}$ numbers are found in table S4. $\mathbf{c ~ C a}^{2+}$-imaging signals evoked by the addition of cytisine. $\mathbf{d}$ Chemical structures of the tested nAChR agonists. e, f Manual patch clamp recordings of the responses of LUHMES neurons evoked by the application of $10 \mu \mathrm{M}$ nicotine for $5 \mathrm{~s}$. e Firing of multiple action potentials with a long-lasting depolarization of the membrane potential $(n=28)$ recorded in current-clamp. f Slowly inactivating inward current $(n=12)$ measured in voltageclamp

neurons held in current-clamp evoked either tonic $(n=28$, Fig. 1e) or phasic ( $n=14$, data not shown) action potential firing. Furthermore, voltage-clamp recordings revealed that 
cells responded with a fast-activating and slowly inactivating inward current ( $n=12$, Fig. 1f). These findings confirm the presence of functional nAChRs on LUHMES neurons as shown by $\mathrm{Ca}^{2+}$-imaging. Moreover, the observed longlasting depolarization of the membrane potential over the entire application period indicates a strong contribution of non- $\alpha 7$ nAChRs (e.g., $\alpha 4 \beta 2$ or $\alpha 4 \beta 4$ subtypes) (Elliott et al. 1996; Wu et al. 2006; Mihalak et al. 2006; Rollema et al. 2007; Alijevic et al. 2020).

\section{Investigation of $\mathbf{n A C h R}$ subtype composition in LUHMES cells}

To profile LUHMES neurons for functional neurotoxicity studies, we used additional pharmacological tools to shed light on the nAChR subtype composition. First, we tested whether antagonists of nAChRs modulated the
$\mathrm{Ca}^{2+}$-responses. The non-selective $\mathrm{nAChR}$ antagonist tubocurarine (Tubo) (Jonsson et al. 2006) has a long history in toxicology and is one component of an arrow poison for hunting. Application of Tubo antagonized the responses evoked by nicotine (Fig. 2a), ACh (Fig. 2b) and varenicline concentration-dependently $\left(\mathrm{pIC}_{50}\right.$ values $\sim 6.1$ ) (Fig. 2c). Tubo completely blocked the responses to all three agonists at concentrations $>10 \mu \mathrm{M}$, indicating that the entire agonisttriggered $\mathrm{Ca}^{2+}$-signaling was mediated by nAChRs.

To further dissect the nAChR subtypes involved in LUHMES responses, we researched the effects of other antagonists. Methyllycaconitine (MLA) is more potent (low $\mathrm{nM}$ range) on the $\alpha 7 \mathrm{nAChR}$ than on other receptor combinations (Puchacz et al. 1994; Gopalakrishnan et al. 1995; Palma et al. 1996; Buisson et al. 1996; Capelli et al. 2011). Application of MLA (Fig. 2d) yielded a $\mathrm{pIC}_{50}$ of 6.3 in our cell system (Fig. 2f). This low affinity indicates that mainly
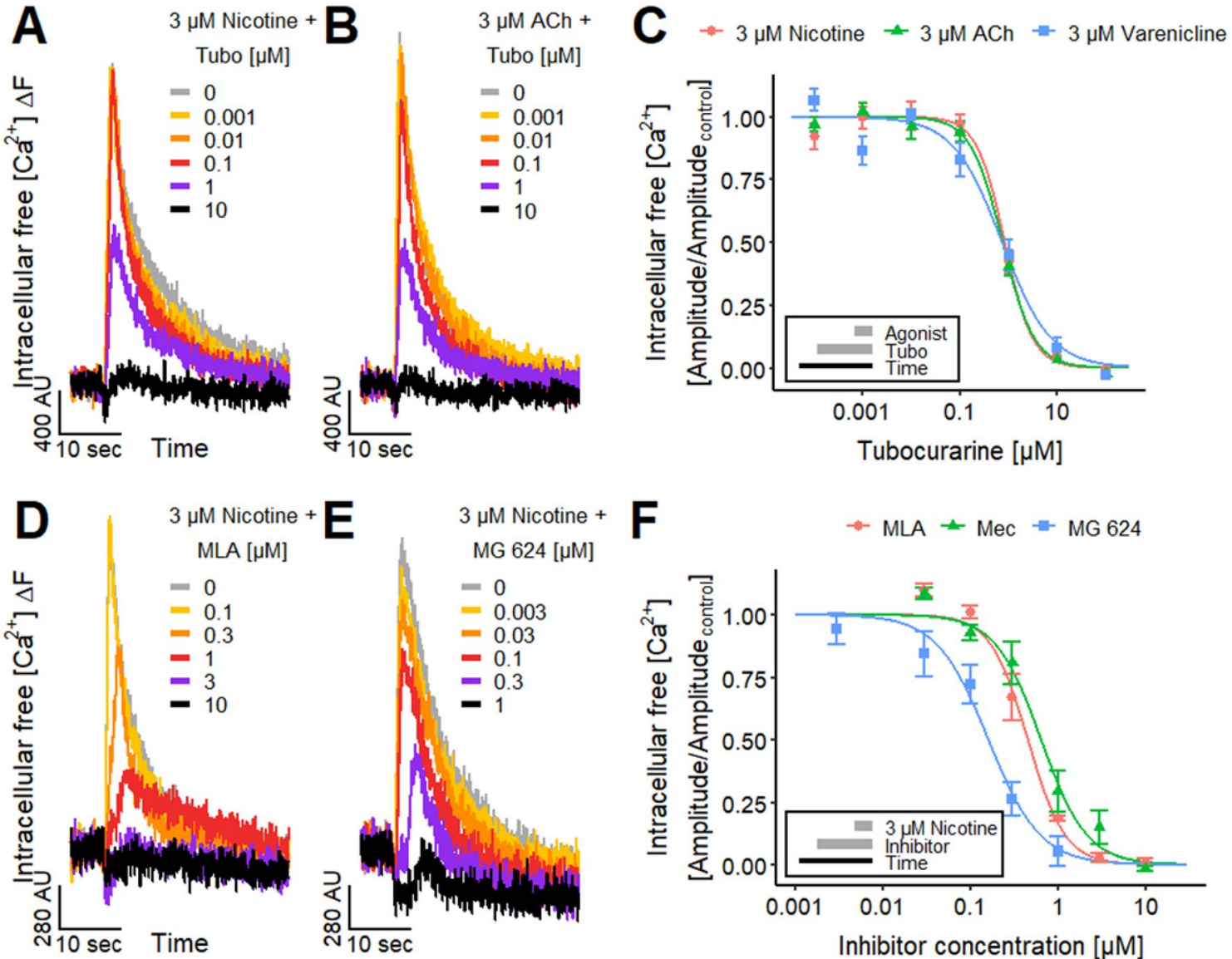

\section{E}

$-M L A \nrightarrow M e c-M G 624$

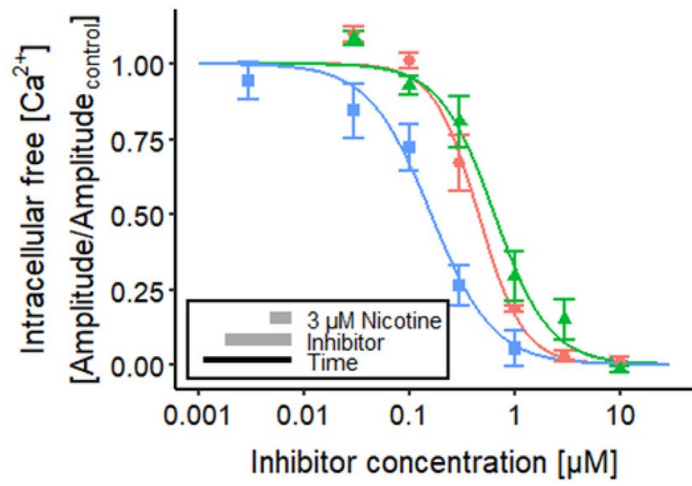

Fig. 2 Characterization of the nAChRs. a, $\mathbf{b} \mathrm{Ca}^{2+}$-imaging signals of the effects of the pre-applied non-selective nAChR antagonist tubocurarine (Tubo) on the responses of LUHMES neurons triggered by a $3 \mu \mathrm{M}$ nicotine and b $3 \mu \mathrm{M}$ ACh. c Inhibitory effect of Tubo on the signals evoked by the acute exposure to $3 \mu \mathrm{M}$ of nicotine, ACh and varenicline. The resulting $\mathrm{pIC}_{50}$ values were $6.08 \pm 0.04$ for nicotine, $6.13 \pm 0.04$ for ACh and $6.13 \pm 0.09$ for varenicline. $\mathbf{d}$, e Traces of the effects of d MLA and e MG 624 on the $\mathrm{Ca}^{2+}$-imaging signals

stimulated by $3 \mu \mathrm{M}$ nicotine. f Concentration-response curves for the effects of MLA, mecamylamine (Mec) and MG 624 on the responses triggered by the acute exposure to $3 \mu \mathrm{M}$ nicotine. The $\mathrm{pIC}_{50}$ values were $6.33 \pm 0.04$ for MLA, $6.17 \pm 0.05$ for Mec and $6.80 \pm 0.07$ for MG 624. Note the treatment schemes (lower left corner), illustrating the experimental design. Detailed data on $n$ numbers are found in table S4 
non- $\alpha 7 \mathrm{nAChRs}$ are responsible for the $\left[\mathrm{Ca}^{2+}\right]_{\mathrm{i}}$ response. The LUHMES $\mathrm{pIC}_{50}$ was similar to previously reported $\mathrm{pIC}_{50}$ values for human $\alpha 4 \beta 2$ expressed in cell lines (Buisson et al. 1996; Capelli et al. 2011), while it was different from the reported $\mathrm{pIC}_{50}$ values for $\alpha 7, \alpha 3 \beta 4, \alpha 1 \beta 1 \delta \varepsilon$ and $\alpha 6$-containing ( $\alpha 6 / 3 \beta 2 \beta 3)$ nAChRs (Capelli et al. 2011). This points towards a major contribution of $\alpha 4 \beta 2$ to the response evoked by nicotine in LUHMES.

To further substantiate the findings resulting from the MLA experiments, we applied the non-competitive nAChR antagonist mecamylamine (Mec) (Papke et al. 2008; Capelli et al. 2011). This drug shows higher potency for $\alpha 4 \beta 2$ and $\alpha 3 \beta 4 \mathrm{nAChRs}$ compared to the a7 nAChR (Capelli et al. 2011). The $\mathrm{pIC}_{50}$ value of 6.2 (Fig. $2 \mathrm{f}$ ) is comparable to literature data of $\sim 6.1$ for human $\alpha 4 \beta 2$ (Chavez-Noriega et al. 2000; Capelli et al. 2011) and 6.6 for human $\alpha 3 \beta 2$ (ChavezNoriega et al. 2000), while it was different from reported
$\mathrm{pIC}_{50}$ values for $\alpha 7, \alpha 3 \beta 4, \alpha 1 \beta 1 \delta \varepsilon$ and $\alpha 6$-containing $(\alpha 6 / 3 \beta 2 \beta 3)$ nAChRs (Capelli et al. 2011).

Finally, we confirmed our previous results by applying MG 624, a slightly more potent nAChR antagonist (Gotti et al. 2000; Capelli et al. 2011). The LUHMES pIC ${ }_{50}$ of 6.8 (Fig. 2e, f) is comparable to literature $\mathrm{pIC}_{50}$ values of 6.8 for $\alpha 4 \beta 2,6.6$ for $\alpha 3 \beta 4,6.9$ for $\alpha 7$ and 7.3 for $\alpha 1 \beta 1 \delta \varepsilon$ (Capelli et al. 2011).

These antagonist data provided indirect evidence for a contribution of neuronal non- $\alpha 7$ nAChRs, e.g., $\alpha 4 \beta 2$ and/ or $\alpha 3$-containing nAChRs, to the $\left[\mathrm{Ca}^{2+}\right]_{\mathrm{i}}$ responses of LUHMES evoked by nicotine. To address this issue more directly, we made use of the neuronal non- $\alpha 7 \mathrm{nAChRs}$ agonist ABT 594 (Donnelly-Roberts et al. 1998; Michelmore et al. 2002). We found a $\mathrm{pEC}_{50}$ value of 8.4 (Fig. 3b, c), which strongly suggests a presence of functional non- $\alpha 7$ nAChRs on LUHMES. In fact, the potency of this drug
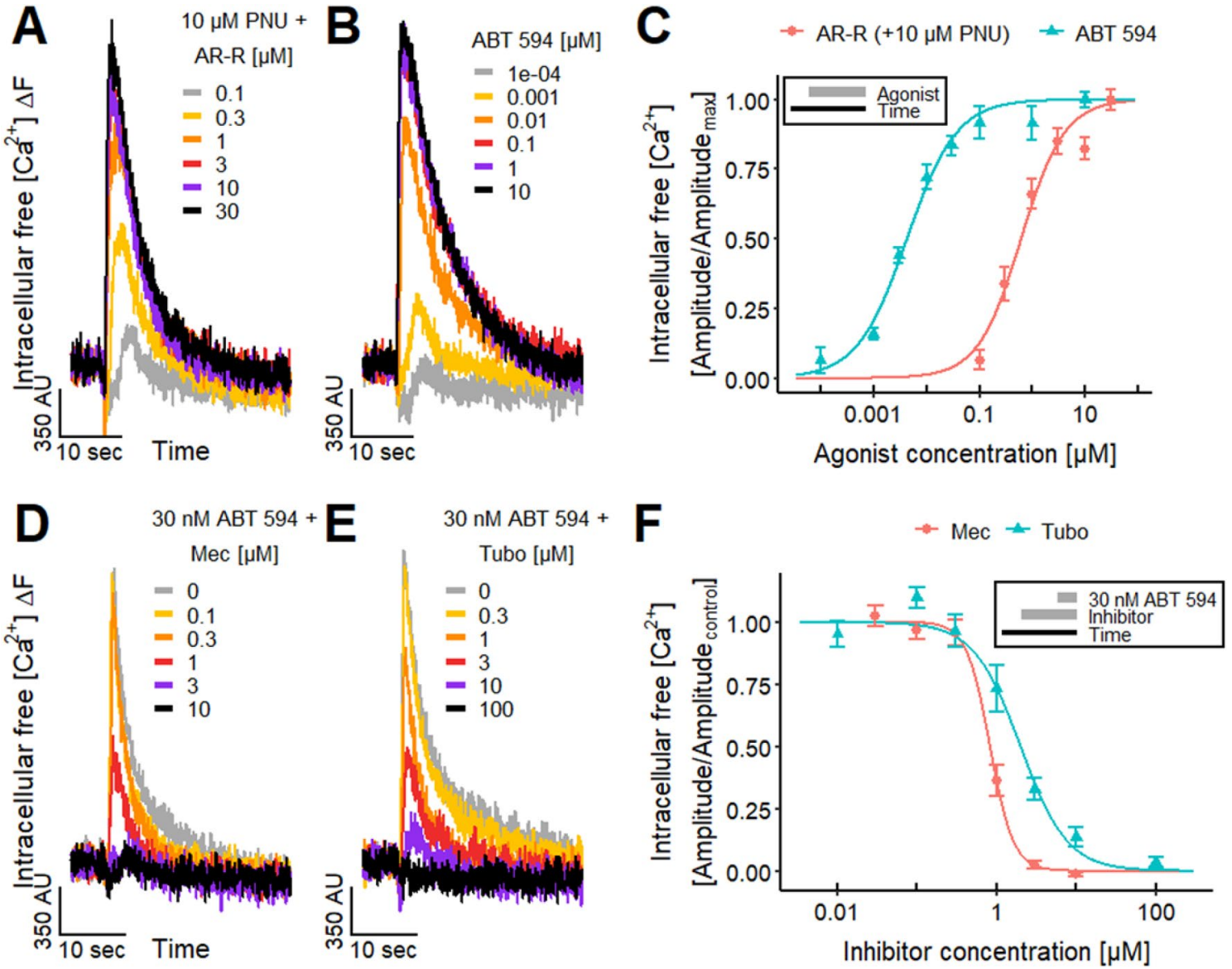

Fig. 3 Differential agonist responses on nAChRs. a, b Signals of $\mathrm{Ca}^{2+}$-imaging triggered by the selective $\alpha 7 \mathrm{nAChR}$ agonist a AR-R 17779 (AR-R), after the pretreatment with $10 \mu \mathrm{M}$ PNU-120596 (PNU), a positive allosteric modulator of $\alpha 7 \mathrm{nAChR}$, and the selective non- $\alpha 7$ nAChR agonist b ABT 594. c Agonistic effect of AR-R in presence of $10 \mu \mathrm{M}$ PNU and ABT 594 yielded $\mathrm{pEC}_{50}$ values of $6.20 \pm 0.05$ and $8.36 \pm 0.05$, respectively. d, e $\mathrm{Ca}^{2+}$-imaging traces

of the effects of $\mathbf{d} \mathrm{Mec}$ and $\mathbf{e}$ Tubo, which were preincubated for $4.5 \mathrm{~min}$, on the response of the LUHMES neurons evoked by $30 \mathrm{nM}$ ABT 594. f The concentration-response curves of the effects of Mec and Tubo on the response evoked by $30 \mathrm{nM}$ ABT 594 resulted in $\mathrm{pIC}_{50}$ values of $6.08 \pm 0.03$ and $5.70 \pm 0.05$, respectively. Note the treatment schemes, illustrating the experimental design. Detailed data on n numbers are found in table S4 
in the LUHMES system was even higher than previously reported for other cells (Donnelly-Roberts et al. 1998; Michelmore et al. 2002). This might be explained by the presence of multiple $\mathrm{nAChR}$ subtypes on LUHMES neurons, because the potency of ABT 594 depends on the $\mathrm{nAChR}$ subtype (Michelmore et al. 2002), as also described for other nAChR agonists (Chavez-Noriega et al. 2000; Jonsson et al. 2006; Capelli et al. 2011). As internal consistency check, we blocked ABT 594 responses with the nAChR antagonists Mec (Fig. 3d) and Tubo (Fig. 3e). The pIC $\mathrm{IC}_{50}$ values of 6.1 for Mec and 5.7 for Tubo (Fig. 3f) are similar to the values that we obtained before for both antagonists for nicotine (Fig. 2f).

In summary, our data demonstrate a functional expression of neuronal non- $\alpha 7$ nAChRs on LUHMES neurons and highlight the capability of this test system for detecting agonistic and antagonistic effects on nAChRs.

\section{Identification of $a 7$ nAChR on LUHMES}

As the gene expression data suggested that $\alpha 7 \mathrm{nAChRs}$ are highly expressed in LUHMES (Fig. S1), we investigated the functional role of this receptor subtype. First, we checked the effect of the selective $\alpha 7 \mathrm{nAChR}$ agonist AR-R 17779 (ARR) (Mullen et al. 2000; Michelmore et al. 2002; Papke et al. 2004) on $\left[\mathrm{Ca}^{2+}\right]_{\mathrm{i}}$. We failed to detect a response $(n \geq 13$, data not shown). The most likely reason is a very fast inactivation of the $\alpha 7 \mathrm{nAChR}$ (Elliott et al. 1996; Mihalak et al. 2006). This has also been described for other $\alpha 7 \mathrm{nAChR}$ agonists in $\mathrm{Ca}^{2+}$-imaging experiments (Dickinson et al. 2007; Gill et al. 2013; Chatzidaki et al. 2015; Larsen et al. 2019). As receptor desensitization can lead to technical challenges when investigating nicotinic agonists, several positive allosteric modulators including PNU-120596 (PNU) have been developed to counteract this phenomenon. We used here the selective positive allosteric modulator of the $\alpha 7$ nAChR, PNU-120596 (PNU). This compound can slow the $\alpha 7 \mathrm{nAChR}$ inactivation, and it, therefore, enables the detection of the $\alpha 7 \mathrm{nAChR}$-mediated response (Hurst et al. 2005; Dickinson et al. 2007; Ng et al. 2007; Grønlien et al. 2007; Papke et al. 2009; Williams et al. 2011; Chatzidaki et al. 2015; Larsen et al. 2019). Under these conditions (presence of PNU), the cells responded concentration-dependently to the stimulation with AR-R (Fig. 3a). The $\mathrm{pEC}_{50}$ value of 6.2 (Fig. 3c) indicates the presence of functional $\alpha 7 \mathrm{nAChRs}$. The LUHMES $\mathrm{pEC}_{50}$ value for AR-R is high, compared to a previously reported value for rat $\alpha 7$ expressed in Xenopus laevis oocytes $\left(\mathrm{pEC}_{50}=5\right.$; Papke et al. 2004). This difference is most likely due to the increased agonist potency induced by the allosteric enhancer PNU, as previously described (Hurst et al. 2005; Grønlien et al. 2007).

To control for the $\alpha 7$ specificity of PNU in the LUHMES system, we tested, whether it would also enhance signaling of other receptors. In control experiments, cells were stimulated with $1 \mu \mathrm{M} \alpha, \beta$-meATP (P2X receptor agonist (Bianchi et al. 1999; Khakh and North 2012; Loser et al. 2021)) and different concentrations of ABT 594 (non- $\alpha 7$ nAChR agonist). In both cases, no differences between recordings with and without PNU were detected (Fig. S2). We, therefore, conclude that PNU did not enhance $\left[\mathrm{Ca}^{2+}\right]_{\mathrm{i}}$ responses in general, but only those of the $\alpha 7 \mathrm{nAChR}$.

In summary, the $\alpha 7 \mathrm{nAChR}$-selective tool compounds showed consistent responses and interactions, thereby showing functional expression of $\alpha 7 \mathrm{nAChRs}$ on LUHMES neurons.

\section{Direct effect of neonicotinoids on otherwise untreated LUHMES cultures}

After demonstrating the presence of functional nAChRs on LUHMES and establishing the test system's suitability to study nAChR-based toxicity, we investigated a subset of six neonicotinoids, namely acetamiprid (Aceta), imidacloprid (Imida), clothianidin (Cloth), thiacloprid (Thiac), thiamethoxam (Thiam) and dinotefuran (Dino), using $\mathrm{Ca}^{2+}$-imaging as endpoint (Fig. 4a, b). All compounds, except for Thiam and Dino, evoked responses, which we calibrated to the maximum effect observed at $10 \mu \mathrm{M}$ nicotine (Fig. 4c). We determined $\mathrm{pEC}_{25}$ values, as the responses triggered by the neonicotinoids did not reach the $50 \%$ response level in the tested concentration range $(\leq 100 \mu \mathrm{M})$. A comparison of the responses of the four active compounds to those of nicotine based on $\mathrm{pEC}_{25}$ values indicated that the pesticides had a two orders of magnitude lower potency, but triggered clear responses at 10-100 $\mu \mathrm{M}$ concentrations (Fig. 4d). Our data also indicate that the four active pesticides have lower potencies than nicotine or the endogenous neurotransmitter ACh. One straightforward explanation for the potency data observed may be the different affinities of the compounds for the set of $n A C h R s$ expressed on LUHMES cells. Binding assays using $\alpha 4 \beta 2 \mathrm{nAChR}$ have suggested such potency differences (Tomizawa and Casida 2005).

Our data show that also human cells react to neonicotinoids with changes of $\left[\mathrm{Ca}^{2+}\right]_{i}$, as has been shown earlier for Aceta and Imida in other mammalian cells, i.e., primary rat neuronal cultures (Kimura-Kuroda et al. 2012). Effects of neonicotinoids on human neurons may have remained hitherto relatively unnoticed, as many tests only focus on endpoints related to cell viability and cell morphology. For instance, we did not observe any effect of neonicotinoids on the neurite outgrowth of LUHMES cells (Fig. S3). Our finding that human neuronal cells react to neonicotinoids demonstrates the importance of functional assays to assess potential adverse effects on neurons.

To confirm the important findings from $\mathrm{Ca}^{2+}$-imaging experiments, we additionally performed manual patch clamp 


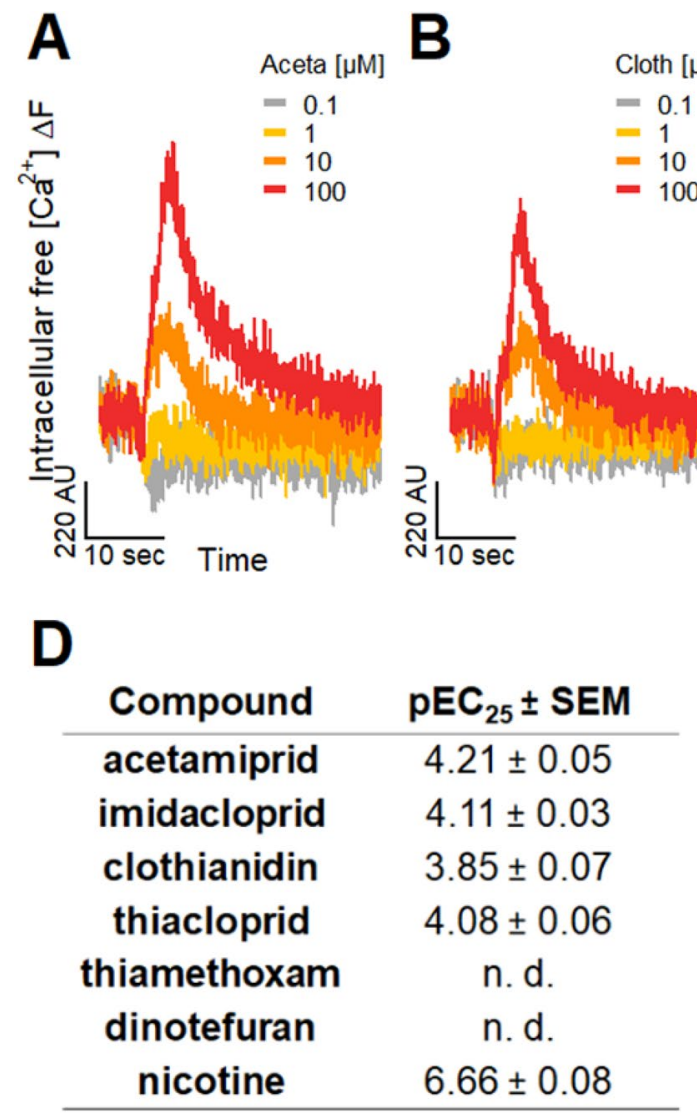

Fig. 4 Effect of neonicotinoids on LUHMES neurons. $\mathbf{a}, \mathbf{b}$ Traces of $\mathrm{Ca}^{2+}$-imaging show the effects of the neonicotinoids a Aceta and $\mathbf{b}$ Cloth on LUHMES neurons. c Concentration-dependent effect of the neonicotinoids Aceta, Imida, Cloth, Thiac, Thiam and Dino and the positive control nicotine. Amplitudes were normalized to the maximal amplitude evoked by nicotine. Note the treatment scheme (upper left corner), illustrating the experimental design. d Table with cor-

recordings (Fig. 4e). Aceta $(100 \mu \mathrm{M})$ clearly depolarized the cells, but not to a sufficient extent to trigger action potential firing $(n=4)$. The time course of depolarization gives some indication on the types of receptors involved: the long-lasting effect suggests that mainly non- $\alpha 7$ nAChRs contributed to the current (Mihalak et al. 2006; Rollema et al. 2007; Alijevic et al. 2020). With $\alpha 7 \mathrm{nAChR}$ activation as main mode of action, a rapid depolarization followed by a timely repolarization would have been observed during the application. However, it cannot be excluded from the data available that $\alpha 7 \mathrm{nAChRs}$ at least partially were co-activated, together with non- $\alpha 7$ nAChRs.
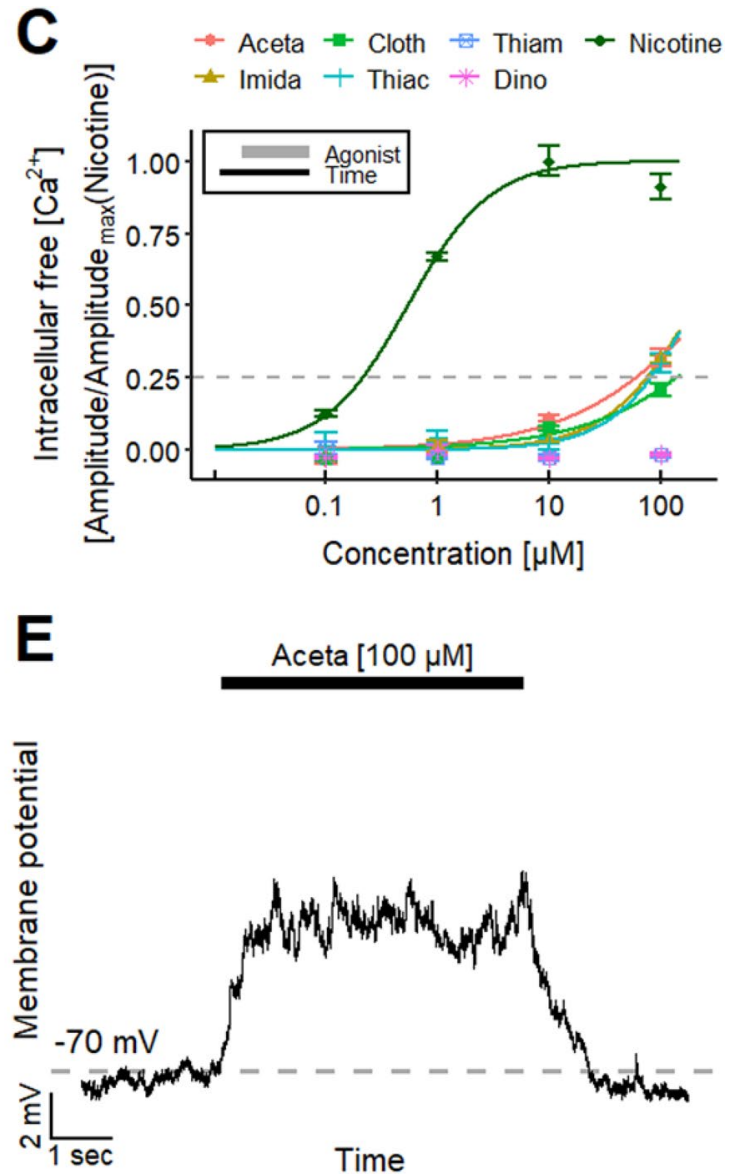

responding $\mathrm{pEC}_{25}$ values for the tested neonicotinoids and nicotine. Detailed data on $\mathrm{n}$ numbers are found in table S6. e Manual patch clamp recording of a long-lasting depolarization of the membrane potential during the application of $100 \mu \mathrm{M}$ Aceta for $5 \mathrm{~s}(n=4)$. The Aceta-induced depolarization from a holding potential of $-70 \mathrm{mV}$ was not sufficient to evoke action potential firing

\section{Neonicotinoids effects on $\mathrm{Ca}^{2+}$-signaling of individual LUHMES neurons}

After our initial findings of neonicotinoid effects on human neuronal cultures (LUHMES), it was important to confirm $\left[\mathrm{Ca}^{2+}\right]_{\mathrm{i}}$ changes on the level of single cells. We used a $\mathrm{Ca}^{2+}$-imaging approach with high spatial resolution, and found that the positive control nicotine triggered a rapid rise in $\left[\mathrm{Ca}^{2+}\right]_{\mathrm{i}}$ in most neuronal cell bodies as well as in the neurite network (Fig. 5a). Aceta triggered a response only in a subset of cell bodies and in parts of the neurite network. Some cells clearly did not 
A
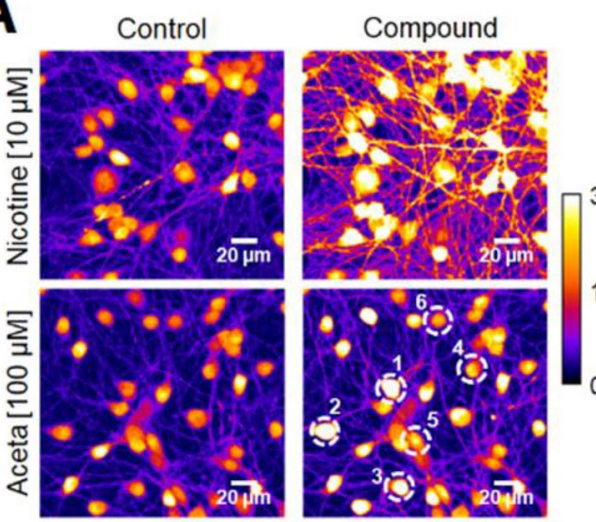

C
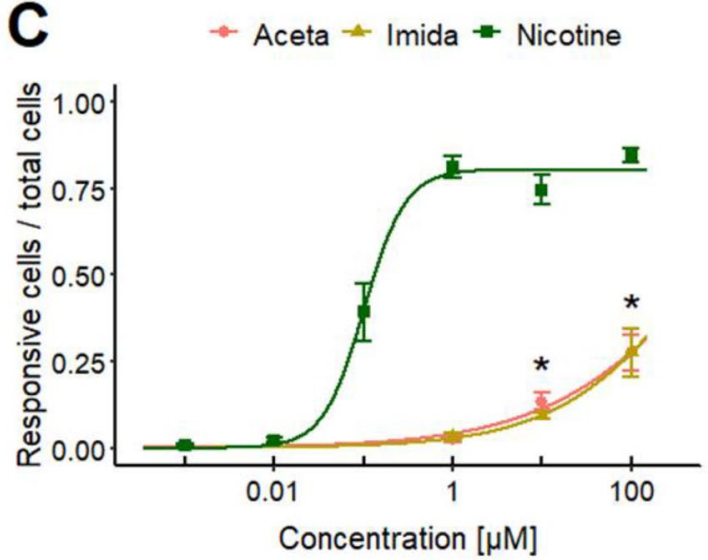

Fig. 5 Effects of neonicotinoids on $\mathrm{Ca}^{2+}$-signaling on the level of individual neurons. a LUHMES neurons during control and during the application of $10 \mu \mathrm{M}$ nicotine and $100 \mu \mathrm{M}$ Aceta. Pictures of single-cell $\mathrm{Ca}^{2+}$-imaging recordings were taken with the Cell Observer (Carl Zeiss Microscopy). Images are shown in false color to enhance the interpretability. b Traces of single-cell $\mathrm{Ca}^{2+}$-imaging recordings of six cells (marked in a) with and without response to the application of $100 \mu \mathrm{M}$ Aceta. Threshold for response detection is defined as mean $+3 \times$ SD of negative control recordings. c Percentage of cells that responded to the application of nicotine, Aceta and Imida in single-cell $\mathrm{Ca}^{2+}$-imaging recordings. Changes are significant

respond (Fig. 5a, b). The concentration-dependency of the responding cells was quantified for nicotine, Aceta and Imida (Fig. 5c). The curves looked similar to the concentration-response curves obtained with the high-throughput system (Fig. 4c). At $1 \mu \mathrm{M}$ nicotine, the relative number of responsive cells reached its maximum of about $80 \%$. For Aceta and Imida, cell responses were significantly increased at $10 \mu \mathrm{M}$, and they comprised about one-quarter of all cells at the highest test concentration of $100 \mu \mathrm{M}$. We also detected responses of the LUHMES neurons to the application of Cloth and Thiac, but not for Thiam and Dino at their highest tested concentration (Fig. 5d). To further confirm our findings from high-throughput imaging, we used Tubo also in single-cell recordings. The nAChR

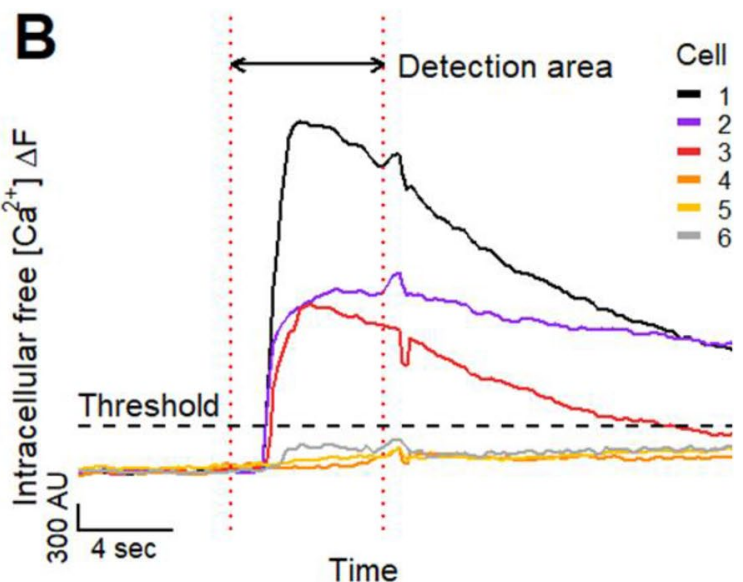

D

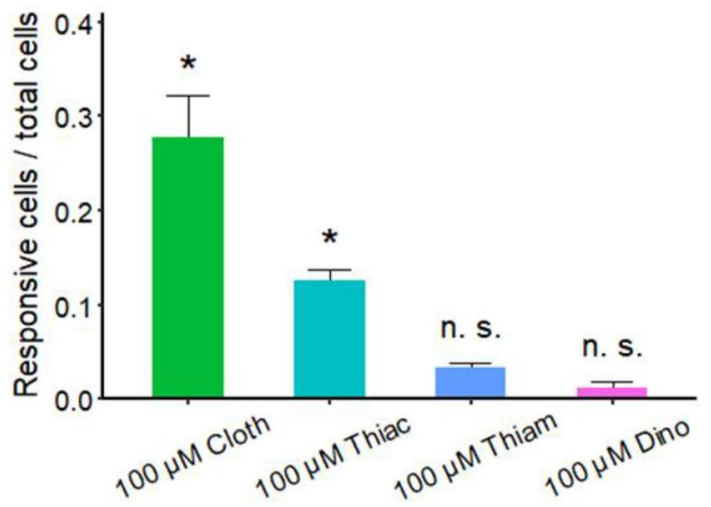

$\left({ }^{*} p<0.05, t\right.$ test) for $10 \mu \mathrm{M}$ Aceta and Imida. Using more stringent ANOVA with Dunnett's post hoc test, there was a significant difference for $100 \mu \mathrm{M}$, but only a trend $(p>0.05$ for $10 \mu \mathrm{M})$. This range of effect significance agrees well with calculations of the Imida benchmark concentration $\left(\mathrm{BMC}_{10}=11.2 \mu \mathrm{M}\right)$ and its upper $95 \%$ confidence limit $\left(\mathrm{BMCU}_{10}=26 \mu \mathrm{M}\right)$. d Fraction of cells reacting to Cloth, Thiac, Thiam and Dino at a concentration of $100 \mu \mathrm{M}$. Note the enlarged $y$-axis. c, d Statistical significance was determined against negative control recordings ( $*$, significant by ANOVA; n. s., not significant). Detailed data on $\mathrm{n}$ numbers and percentages of responsive cells are found in table S7 and S8, respectively

antagonist concentration-dependently reduced the number of cells responding to Aceta $(100 \mu \mathrm{M}$, Fig. S4). In summary, these findings confirm the data obtained with highthroughput $\mathrm{Ca}^{2+}$-imaging measurements. They suggest an impact of Aceta, Imida, Cloth and Thiac on $\mathrm{Ca}^{2+}$-signaling of LUHMES neurons; they also confirm the low/absent effectiveness of Thiam and Dino. It remains unclear, why the otherwise quite homogeneous LUHMES cultures show response heterogeneity at the single cell level. Since LUHMES form an interactive network, different cells in the network differ by their interconnection, their neighborhood and their firing history, and all this may contribute to differential responsiveness to nicotine or neonicotinoids (Loser et al. 2021). 


\section{The role of $a 7 \mathrm{nAChR}$ for responses to neonicotinoids in LUHMES and SH-SY5Y neurons}

The $\alpha 7 \mathrm{nAChR}$ is widely distributed in the central nervous system and is involved in the modulation of neurotransmitter release (McGehee et al. 1995; Gray et al. 1996; Alkondon et al. 1999; Levin et al. 2006; Gotti et al. 2006; Zoli et al. 2015). To address the role of $\alpha 7 \mathrm{nAChRs}$ in neonicotinoid effects, we performed $\mathrm{Ca}^{2+}$-imaging experiments in the presence of PNU. While PNU had no effect by itself on nonstimulated cells, it drastically enhanced the $\left[\mathrm{Ca}^{2+}\right]_{\mathrm{i}}$-increase (peak and duration) triggered by, e.g., Cloth or Thiac (Fig. 6a, b). A systematic comparison of all six compounds used in our study showed that PNU significantly enhanced the responses to Aceta, Imida, Cloth and Thiac. Thiam and Dino had no effect, independent of the presence or absence of PNU (Fig. 6c). The enhancing effect of PNU indicates an activation of human $\alpha 7 \mathrm{nAChRs}$ by Aceta, Imida, Cloth and Thiac, but not Thiam and Dino. These data are in good agreement with a study by Cartereau et al. (2018). An agonist activity of Imida on $\alpha 7 \mathrm{nAChRs}$ has also been described in other systems (Yamamoto et al. 1998; Ihara et al. 2003).

As the stimulation of human neuronal nAChRs has important toxicological implications, we checked main findings in a second, entirely independent test system: SH-SY5Y human neuroblastoma cells. Such cultures have been used earlier to prepare cell membranes containing nAChRs and also to measure the efflux of ${ }^{86} \mathrm{Rb}^{+}$(Lukas et al. 1993; Tomizawa and Casida 1999). Here, we characterized the receptor subunit expression profile during retinoic acid-induced differentiation, and we found particularly high and consistent (over time) levels of $\alpha 7$ (Figs. 7a and S5A). Upon exposure
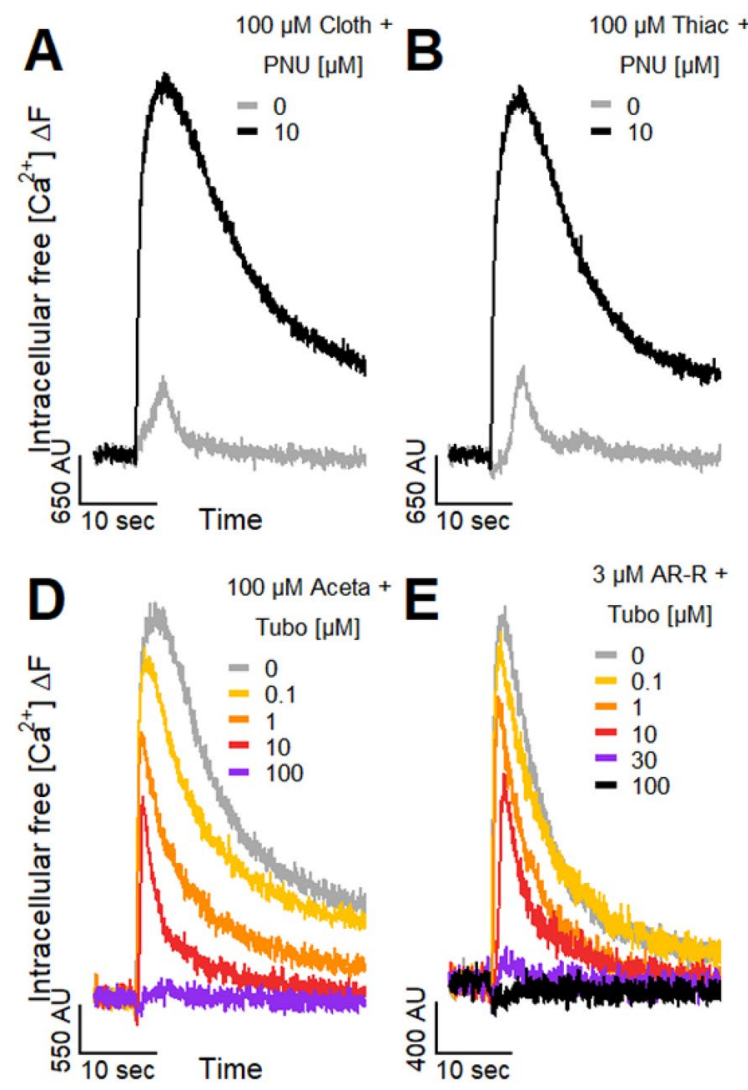

Fig. 6 Effect of neonicotinoids on $\alpha 7$ nAChR. a, b $\mathrm{Ca}^{2+}$-imaging traces of the effects of the neonicotinoids a Cloth and $\mathbf{b}$ Thiac during control and in the presence of $10 \mu \mathrm{M}$ PNU, which was preincubated for $4.5 \mathrm{~min}$. c Effects of the neonicotinoids Aceta, Imida, Cloth, Thiac, Thiam and Dino $(100 \mu \mathrm{M})$ on the $\mathrm{Ca}^{2+}$-imaging signal of LUHMES neurons in absence and presence of $10 \mu \mathrm{M}$ PNU. Statistical significance was determined between the recordings of the neonicotinoids without PNU and negative control recordings (*, significant; n. s., not significant) and between the recordings of each neonicotinoid without and with PNU (\#, significant; n. s., not significant). d, e Traces of $\mathrm{Ca}^{2+}$-imaging showing the effect of pre-applied
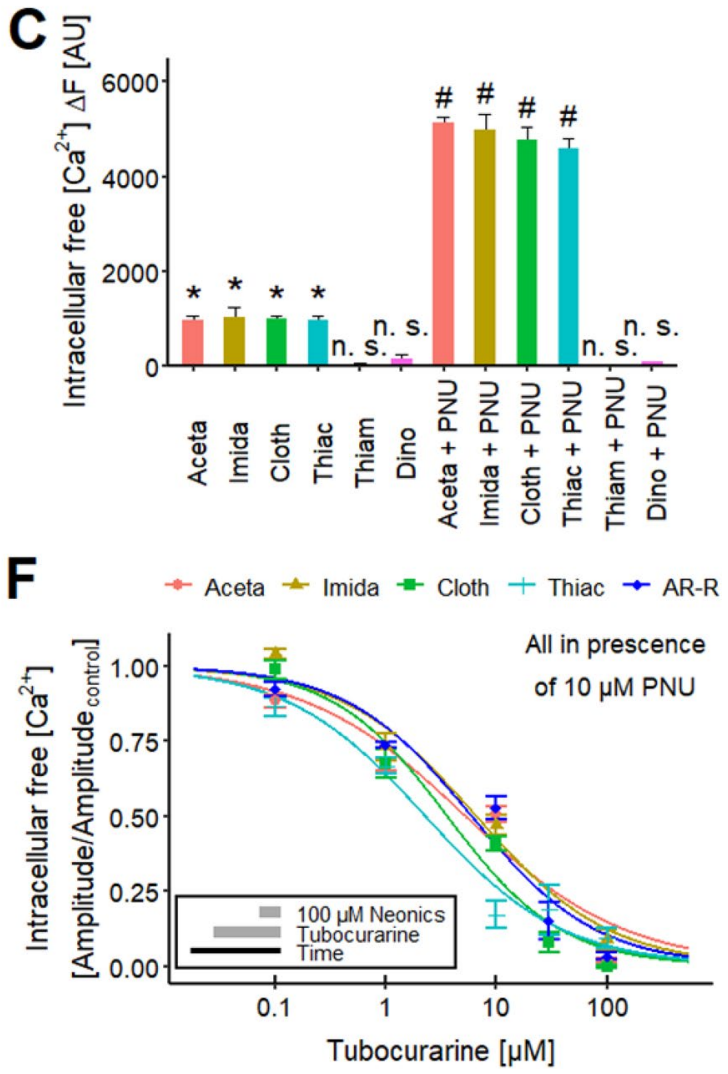

tubocurarine (Tubo) on the signals evoked by d $100 \mu \mathrm{M}$ Aceta and e $3 \mu \mathrm{M}$ AR-R, both in the presence of pre-applied $10 \mu \mathrm{M}$ PNU. f The concentration-response curves illustrate the effects of Tubo on the response of the LUHMES neurons to the acute exposure to the neonicotinoids Aceta, Imida, Cloth and Thiac $(100 \mu \mathrm{M})$ and the $\alpha 7$ agonist AR-R $(3 \mu \mathrm{M})$. All recordings were performed in the presence of $10 \mu \mathrm{M}$ PNU, which was preincubated for $4.5 \mathrm{~min}$. The resulting $\mathrm{pIC}_{50}$ values were $5.28 \pm 0.10,5.18 \pm 0.09,5.45 \pm 0.08,5.64 \pm 0.08$ and $5.22 \pm 0.09$ for Aceta, Imida, Cloth, Thiac and AR-R, respectively. Note the treatment scheme (lower left corner), illustrating the experimental design. Detailed data on n numbers are found in table S6 


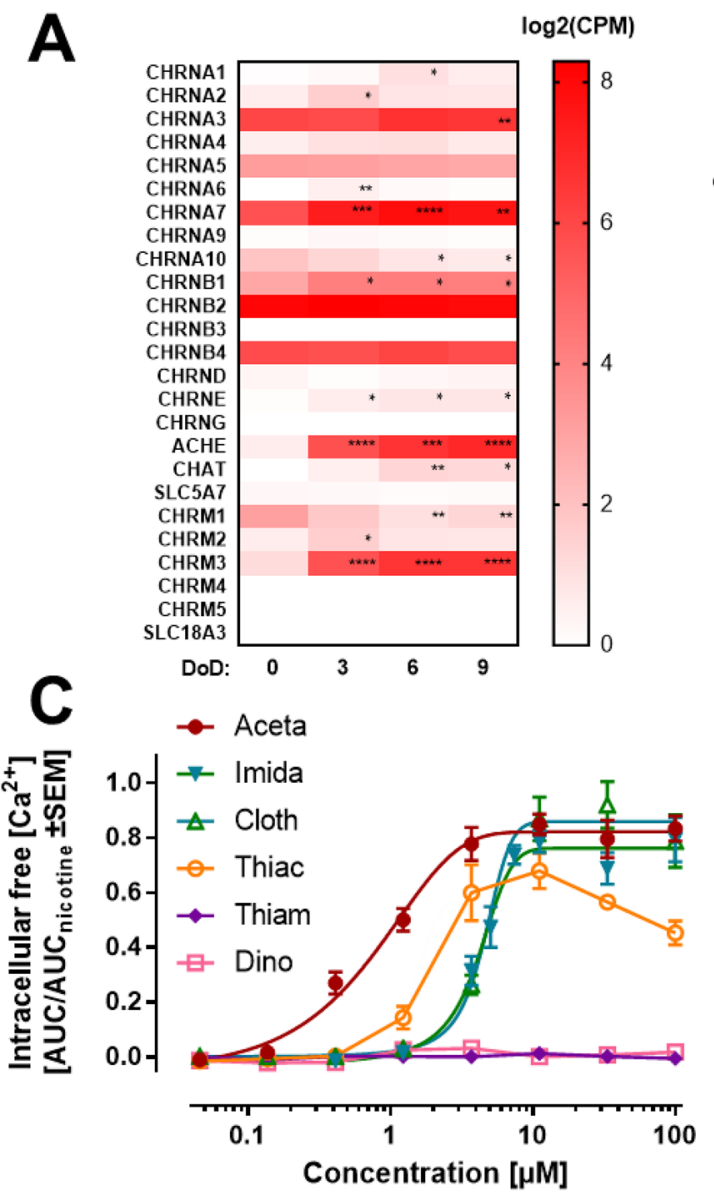

Fig. 7 Nicotine signaling in SH-SY5Y cells. a The expression of genes coding for nAChR subunits was determined by whole-transcriptome RNA-sequencing during differentiation of SH-SY5Y cells. The raw counts were normalized to counts per million total counts $(\mathrm{CPM})$ and $\log 2$-transformed. Significance of changes between day of differentiation (DoD) zero and DoD3-9 was evaluated by ANOVA with Dunnett's multiple comparison test. $* p<0.05$, $* * p<0.01$, $* * * p<0.001, * * * * p<0.0001$. b The SH-SY5Y cells were differentiated for $72 \mathrm{~h}$, and used on DoD3 for $\mathrm{Ca}^{2+}$-imaging experiments. The increase of the $\left[\mathrm{Ca}^{2+}\right]_{\mathrm{i}}$ triggered by nicotine was measured in the presence or absence of $10 \mu \mathrm{M}$ PNU. The responses were evaluated as the area under the curve (AUC) of the increased fluorescence of the calcium-sensitive dye Fura- 2 for $0-150 \mathrm{~s}$ after compound addition. An example of an original recording is shown in figure S5C.

of 3-day differentiated SH-SY5Y cells to nicotine, a clear, but relatively low increase of $\left[\mathrm{Ca}^{2+}\right]_{i}$ was observed, with a $\mathrm{pEC}_{50}$ value of about 7.0. This response was drastically augmented by the $\alpha 7$ stabilizer/allosteric modulator PNU. The increase in $\left[\mathrm{Ca}^{2+}\right]_{\mathrm{i}}$ triggered by nicotine in the presence of PNU was similar or even higher than the very strong response evoked by $30 \mathrm{mM} \mathrm{KCl} \mathrm{(Figs.} \mathrm{7b} \mathrm{and} \mathrm{S5C).} \mathrm{In} \mathrm{addi-}$ tion, the $\left[\mathrm{Ca}^{2+}\right]_{\mathrm{i}}$ responses stimulated by the neonicotinoids Aceta, Imida, Cloth and Thiac were significantly increased (in efficacy and in potency) in the presence of PNU (Fig. S5D). Under these conditions, the neonicotinoids Aceta,
B
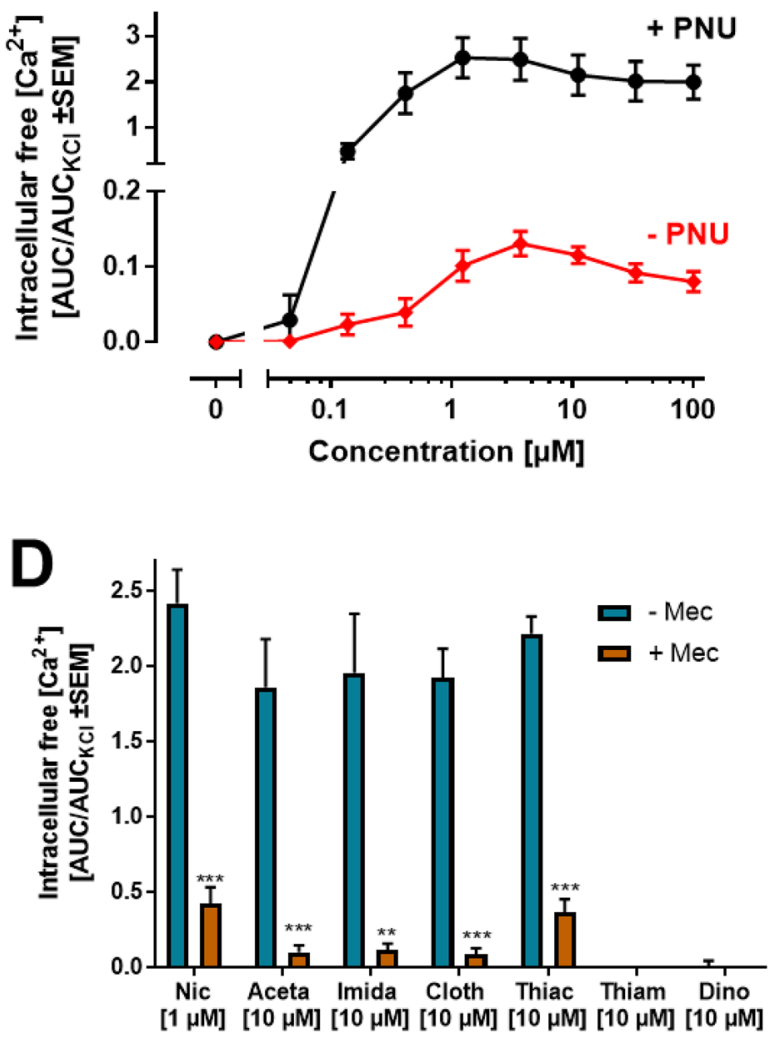

The responses were normalized to the $\left[\mathrm{Ca}^{2+}\right]_{\mathrm{i}}$ response of SH-SY5Y cells after depolarization with $30 \mathrm{mM} \mathrm{KCl}\left(\mathrm{AUC}_{\mathrm{KCl}}\right)(n=4-6)$. $\mathbf{c}$ The $\left[\mathrm{Ca}^{2+}\right]_{\mathrm{i}}$ response of SH-SY5Y cells triggered by Aceta, Imida, Cloth, Thiac, Thiam and Dino was measured in the presence of $10 \mu \mathrm{M}$ PNU. The AUC of the response $(0-150 \mathrm{~s})$ was normalized to the AUC of the response evoked by the treatment of the cells with $11 \mu \mathrm{M}$ nicotine $\left(\mathrm{AUC}_{\text {nicotine }}\right)(n=3)$. The estimated $\mathrm{pEC}_{50}$ values were $6.10 \pm 0.07$, $5.38 \pm 0.03,5.33 \pm 0.01$ and $5.73 \pm 0.01$ for Aceta, Imida, Cloth and Thaic, respectively. d The $\left[\mathrm{Ca}^{2+}\right]_{i}$ responses of SH-SY5Y cells triggered by nicotine, Aceta, Imida, Cloth, Thiac, Thiam and Dino were measured in the presence of $10 \mu \mathrm{M}$ PNU, and the presence or absence of Mec $(125 \mu \mathrm{M})$. The AUC of the responses was normalized to the $\mathrm{AUC}_{\mathrm{KCl}}(n=3-5)$. Significance was evaluated by multiple $t$ tests. $* p<0.05, * * p<0.01, * * * p<0.001$

Imida, Cloth and Thiac triggered $\left[\mathrm{Ca}^{2+}\right]_{\mathrm{i}}$ responses with $\mathrm{pEC}_{50}$ values in the low $\mu \mathrm{M}$ range (Fig. $7 \mathrm{c}$ ). Thiam and Dino had no effect, which fully confirmed our previous findings in LUHMES cultures (Fig. 6c). Cytotoxicity or major changes of receptor expression were not observed for nicotine, Aceta or Imida (Fig. S5A, B). In summary, the SH-SY5Y data provided clear evidence that a subclass of the tested neonicotinoids are agonists on the $\alpha 7 \mathrm{nAChR}$, triggering a $\left[\mathrm{Ca}^{2+}\right]_{\mathrm{i}}$ response in human cells at low $\mu \mathrm{M}$ concentrations (Fig. 7c). The high potency of the neonicotinoids in the neuroblastoma test system might be explained by a high contribution of 
the $\alpha 7 \mathrm{nAChR}$ in these cells, and by the known left-shifting effect of the concentration-response curve by the positive allosteric modulator PNU. Such a potency shift was also observed in LUHMES stimulated with AR-R (Fig. 3c), and it is also known for other agonists (Hurst et al. 2005; Grønlien et al. 2007).

As specificity control for the above-described experiments, we checked whether the responses of nicotine and the four active neonicotinoids were blocked by Mec. The elimination of $\left[\mathrm{Ca}^{2+}\right]_{\mathrm{i}}$ responses under this condition confirms nAChRs as mediators (Fig. 7d). A similar control experiment was also performed in LUHMES cultures. The responses of all four active neonicotinoids, as well as AR-R, were blocked in the presence of PNU by nAChR antagonism (Fig. 6d-f). Thus, the data from two different experimental systems showed that a subgroup of neonicotinoids triggered $\mathrm{Ca}^{2+}$ signaling in human neurons.

\section{Molecular docking studies in support of observed functional effects}

As there was a clear subgrouping of neonicotinoids concerning their functional effect on neurons, we explored whether structural commonalities/differences would support such activity differences. In a first step, some physicochemical parameters relevant to receptor interaction were compared. It was conspicuous that Dino is clearly the most hydrophilic compound of the set and that Thiam has a particularly high polar surface area (Fig. S6A). These extreme features may contribute to the fact that the two compounds behaved differently than the other four neonicotinoids, but the explanatory value of these data is quite limited.

Therefore, we took a more comprehensive approach to identify a possibly differential interaction of the compounds with the receptor. For this purpose, receptor models were established for the $\alpha 7 \mathrm{nAChR}$ and the $\alpha 4 \beta 2 \mathrm{nAChR}$, and molecular docking was performed for all six compounds. The docked poses for each compound were ranked and clustered according to their protein-ligand interaction fingerprints. Then, the highest populated clusters were analyzed (Fig. S6B). This revealed that Aceta, Imida, Cloth and Thiac align well in the known nicotine-binding site. The chloropyridine- and chlorothiazol-moieties of the pesticides pointed towards loops D and E from the complementary subunit and the electronegative nitro and cyano groups reaching out to the tip of the loop C (Fig. S6C). This binding behavior has also been described as "common binding mode", and it has been described earlier (Tomizawa et al. 2008) for both Imida and nicotine, based on co-crystallization of these ligands with the homopentameric ACh binding protein complex (AChBP: the most established model for $\alpha 7$-related structures) (Ihara et al. 2008). Our docking study showed that Thiam almost exclusively exhibited an "inverted" binding mode with the electronegative nitroguanidine group placed close to the area where the other compounds position the chloroheteroaryl substructure, and vice versa (Fig. S6D). Dino showed a binding mode different from all the other compounds. This is most probably due to the lack of a chloroheteroaryl group (Fig. S6E). Thus, the molecular docking experiments indicate that the subgrouping might be determined by the predominant orientation of the compounds in the binding site. The set of high-quality (i.e., more likely) docking poses for Aceta, Imida, Cloth, and Thiac contained many solutions that correspond to the so-called common binding mode (similar to nicotine), but some also suggested an inverted binding mode. In the case of Thiam, only the inverted mode was observed. This might explain the low affinity of Thiam, as the inverted mode has been linked to lower binding affinity (Tomizawa et al. 2008). As Dino binding seemed to differ entirely from that of nicotine or the other compounds, a lowered affinity may be the consequence.

These observations give a molecular rationale for the observed functional differences. However, it is clear that they will require more detailed follow-up by dynamic docking models, including entropy considerations and binding energy calculations. Nevertheless, the preliminary findings presented here give already some potential explanations and better define future research needs.

\section{Modulation of cholinergic responses by neonicotinoids}

An important feature of $\mathrm{nAChR}$ signaling is tachyphylaxis (self-inactivation of the receptor during the signaling process). Under such conditions, signaling may stop even in the presence of a ligand, and signaling cannot be repeated within a certain period after an initial stimulation. This complex behavior is also termed desensitization (Fenster et al. 1997; Quick and Lester 2002; Paradiso and Steinbach 2003; Lester 2004; Rollema et al. 2010; Marks et al. 2010; Capelli et al. 2011; Papke et al. 2011; Campling et al. 2013; Eaton et al. 2014; Arias et al. 2015; Rollema and Hurst 2018). We investigated tachyphylaxis to obtain further evidence for the action of neonicotinoids via the nAChRs. In our experimental setup, the neonicotinoids were added at various concentrations to LUHMES cultures, and thereafter, the $\left[\mathrm{Ca}^{2+}\right]_{\mathrm{i}}$ responses triggered by nicotine were recorded. In cells pretreated with the neonicotinoids, a strong attenuation of the nicotine signaling was observed (Fig. 8a, b). A quantification of the concentration-dependency of the down-modulation resulted in $\mathrm{pIC}_{50}$ values of $\sim 5.4$ for Aceta, Imida, Cloth and Thiac (Figs. 8c, S7A). Thiam and Dino did not show a negative modulation on the nicotine-induced response of LUHMES neurons, again indicating/confirming that they do 

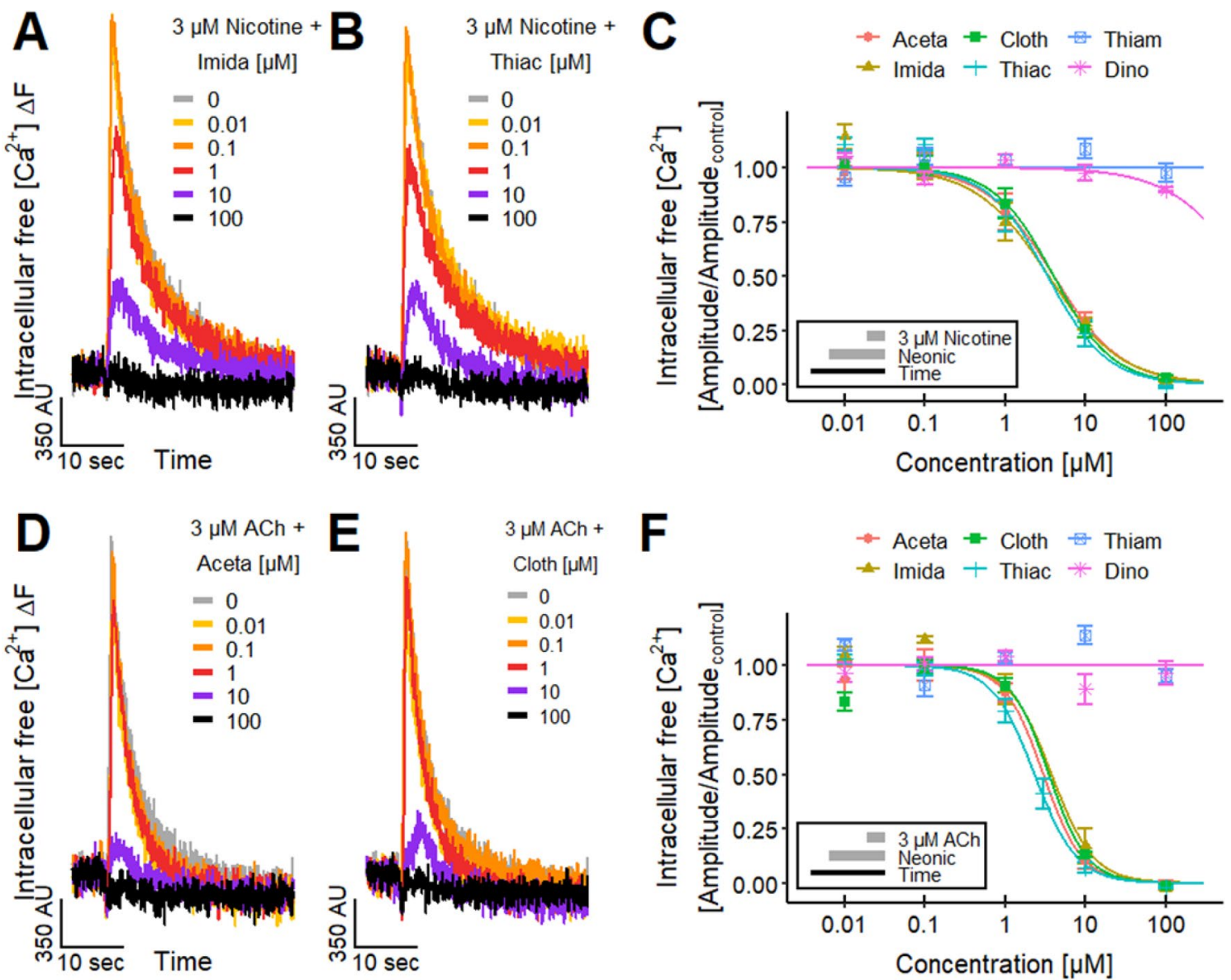

Fig. 8 Effect of neonicotinoids on responses evoked by nicotine and ACh. a, b $\mathrm{Ca}^{2+}$-imaging traces displaying the responses of LUHMES neurons to the acute exposure to $3 \mu \mathrm{M}$ nicotine in the presence of the neonicotinoids a Imida and $\mathbf{b}$ Thiac, which were preincubated for $4.5 \mathrm{~min}$. c Concentration-dependent effects of the pre-applied neonicotinoids Aceta, Imida, Cloth, Thiac, Thiam and Dino on the nicotine-evoked responses. The resulting $\mathrm{pIC}_{50}$ values were $5.40 \pm 0.08,5.47 \pm 0.10,5.41 \pm 0.07$ and $5.48 \pm 0.08$ for Aceta, Imida, Cloth and Thiac, respectively. Thiam and Dino did not show an effect. d, e $\mathrm{Ca}^{2+}$-imaging traces showing the effects of the neoni-

cotinoids $\mathbf{d}$ Imida and e Thiac, which were preincubated for $4.5 \mathrm{~min}$, on the signals evoked by the application of $3 \mu \mathrm{M}$ ACh. $\mathbf{f}$ Effects of the pre-applied neonicotinoids Aceta, Imida, Cloth, Thiac, Thiam and Dino on the response of LUHMES neurons triggered by $3 \mu \mathrm{M}$ $\mathrm{ACh}$. The $\mathrm{pIC}_{50}$ values were $5.53 \pm 0.09,5.43 \pm 0.08,5.46 \pm 0.07$ and $5.64 \pm 0.04$ for Aceta, Imida, Cloth and Thiac, respectively. Thiam and Dino had no effect. Note the treatment schemes (lower left corner), illustrating the experimental design. Detailed data on $n$ numbers are found in table S6

not interact with nAChRs. Experiments performed in SHSY5Y cells confirmed these results (Fig. S5E).

Another set of desensitization experiments was performed using the endogenous neurotransmitter $\mathrm{ACh}$ as stimulus. The resulting $\mathrm{pIC}_{50}$ values for response attenuation were $~ 5.5$ for Aceta, Imida, Cloth and Thiac. Thiam and Dino had no effect (Fig. 8d-f). For Imida, a similar desensitizing effect on ACh-evoked responses has been reported for insect nAChRs (Oliveira et al. 2011) earlier, and such tachyphylaxis phenomena are wide-spread and well documented for ionotropic cholinergic receptors in general (Fenster et al. 1997; Quick and Lester 2002; Paradiso and Steinbach 2003; Lester 2004; Rollema et al. 2010; Marks et al. 2010; Capelli et al. 2011; Papke et al. 2011; Campling et al. 2013; Eaton et al. 2014; Arias et al. 2015;

Rollema and Hurst 2018). The different effects of the neonicotinoids Aceta, Imida, Cloth and Thiac in comparison with Thiam and Dino on the nicotine- and ACh-triggered responses are fully consistent with the differences in agonist activity.

We also explored the issue of a potential cross-tolerance with other receptor systems. This might occur by, e.g., affecting intracellular processes related to $\mathrm{Ca}^{2+}$-signaling. We tested the impact of neonicotinoid pretreatment on signaling via the ionotropic purinergic receptor subtype $\mathrm{P} 2 \mathrm{X} 3$, which has been shown to be functionally expressed in LUHMES (Loser et al. 2021). The response evoked by the agonist $\alpha, \beta$-meATP (Bianchi et al. 1999; Khakh and North 2012; Loser et al. 2021) was not affected by the pre-applied neonicotinoids or nicotine (Fig. S7B). This suggests that 
the tolerance mediated by the neonicotinoids for nicotine is triggered directly on the level of nAChRs.

The desensitizing activity of an agonist occurs typically at concentrations that can activate the receptor, as tachyphylaxis is a typical consequence of receptor activation. However, it is also possible that low concentrations, not sufficient to trigger significant receptor activation may desensitize a receptor. In the latter case, a ligand can have a higher potency for desensitization than for activation of the nAChR (Fenster et al. 1997; Paradiso and Steinbach 2003; Lester 2004; Rollema et al. 2010; Capelli et al. 2011; Arias et al. 2015; Rollema and Hurst 2018). Here, we observed indeed a leftshift of potency in the concentration-response relationship. We determined the lowest active concentration, assuming a benchmark response of $10 \%\left(\mathrm{BMC}_{10}\right)$. These $\mathrm{BMC}_{10}$ values were obtained from the concentration-response curves using a log-logistic model. They ranged between 0.37 and $0.62 \mu \mathrm{M}$ for the four active compounds. The upper end of their $95 \%$ confidence interval (the $\mathrm{BMCU}_{10}$ ), i.e., concentrations having a high likelihood to trigger a biological effect, were at 0.87-3.6 $\mu \mathrm{M}$ (Table S9). These experiments confirm that effects of Imida and related compounds on human neuronal nAChRs are likely to occur in the low $\mu \mathrm{M}$ range.

For confirmation of the desensitizing effect of the neonicotinoids on nAChRs on single cells, we performed $\mathrm{Ca}^{2+}$-imaging experiments on a microscope stage. High or low concentrations of Aceta $(10 \mu \mathrm{M}$ or $100 \mu \mathrm{M})$ were applied prior to a nicotine $(10 \mu \mathrm{M})$ stimulus. The voltagegated $\mathrm{Na}^{+}$channel modulator veratridine (VTD) was used as a positive control at the end of the stimulation series, to verify unaltered overall cell excitability and to exclude possible unspecific effects of Aceta on the electrical activity of the cells. Aceta $(100 \mu \mathrm{M})$ significantly reduced the percentage of responding cells to the ensuing addition of nicotine, whereas the response to VTD was not affected (Fig. S8). These observations support our previous results from highthroughput imaging (Figs. 8C, S7A).

\section{Tolerance triggered by neonicotinoids against the selective agonist ABT 594}

In a final set of experiments, we asked whether the desensitizing effect of the neonicotinoids necessarily involved $\alpha 7$ $\mathrm{nAChR}$. Therefore, cell pretreated with the neonicotinoids were exposed to the non- $\alpha 7 \mathrm{nAChR}$ agonist ABT 594. The $\mathrm{pIC}_{50}$ values for response attenuation were $\sim 5.1$ for Aceta, Imida, Cloth and Thiac (Fig. 9a-c). When given at a concentration of $100 \mu \mathrm{M}$, the compounds blocked the response induced by $30 \mathrm{nM}$ ABT 594 completely. As seen in the previous experiments, Thiam and Dino did not show any modulatory effect. These results further confirm our previous findings, as the $\mathrm{pIC}_{50}$ values were in a similar range as the values obtain for stimulations with nicotine and ACh (Fig. 8).

\section{Exposure considerations and in vitro-to-in vivo comparisons}

When exposure to neonicotinoids is considered, at least three scenarios need to be distinguished (Cimino et al. 2017): intentional exposure, occupational (non-intentional) exposure, normal dietary exposure. Several studies demonstrate a wide-spread use of the compounds for suicidal attempts, and under such conditions, several grams of active pesticide are ingested (Mohamed et al. 2009). While occupational exposure is usually low under most conditions in Europe due to restricted use (closed processes for seed treatment implemented), there are reports on hundreds of symptomatic cases (Marfo et al. 2015). For the general population, acute reference doses (ARfD) have been set by EFSA to, e.g., $25 \mu \mathrm{g} / \mathrm{kg} /$ day for Aceta and $80 \mu \mathrm{g} / \mathrm{kg} /$ day for Imida. Monitoring studies (e.g., in 2018 in Europe (European Food Safety Authority (EFSA) et al. 2020)) found for Aceta a maximal acute exposure of $57 \mu \mathrm{g} / \mathrm{kg} / \mathrm{day}$. Thus, assuming that it is realistic that the ARfD can be exceeded twice, a realistic maximal exposure on a single day may be $114 \mu \mathrm{g} / \mathrm{kg}$ (Aceta) to $160 \mu \mathrm{g} / \mathrm{kg}$ (Imida). In rodent studies, the NOAELs for chronic endpoints was $7-15 \mathrm{mg} / \mathrm{kg}$ for Aceta and this point-of-departure was used also for setting the ARfD due to uncertainties/limitations related to the regulatory developmental neurotoxicity study (EFSA Panel on Plant Protection Products and their Residues (PPR) 2013).

The internal exposure data are relatively limited. For mice, treated with NOAEL levels of Imida and Aceta $(10 \mathrm{mg} / \mathrm{kg})$, the brain levels were around 3-6 ppm, and plasma concentrations were in a similar range $(15-30 \mu \mathrm{M})$ (Ford and Casida 2006). Human data are mostly available for urinary metabolites used for biomonitoring, and the concentrations were maximally in the low $\mathrm{nM}$ range (Zhang et al. 2019; Li et al. 2020; Li and Kannan 2020). Due to the lack of more direct data, we built physiology-based toxicokinetic (PBTK) models to predict plasma and brain concentrations (Table S11). An exposure to Imida $(0.16 \mathrm{mg} / \mathrm{kg}$; corresponding to a maximally expected level in the normal population; see above) was predicted to lead to plasma concentrations in the $0.8-1.6 \mu \mathrm{M}$ range and to brain concentrations of $0.5-1.2 \mu \mathrm{M}$ (Fig. S9). Reverse modelling showed that a brain concentration of $2 \mu \mathrm{M}$ Imida (considered a point-of-departure from our in vitro studies) would be reached after an intake of $0.2 \mathrm{mg} / \mathrm{kg}$ body weight in the average population. The in vitro-in vivo comparisons yield plausible data, in the sense that normal population exposure would normally yield sub- $\mu \mathrm{M}$ concentrations, and that such concentrations would not be sufficient to trigger nAChRs. Vice versa, an uptake 
Fig. 9 Effect of neonicotinoids on responses evoked by ABT 594. a, $\mathbf{b ~ C a}{ }^{2+}$-imaging traces of the effects of the neonicotinoids a Imida and $\mathbf{b}$ Cloth, which were preincubated for $4.5 \mathrm{~min}$, the acute exposure to $30 \mathrm{nM}$ dependent effects of the preapplied neonicotinoids Aceta, Imida, Cloth, Thiac, Thiam and Dino on the ABT 594-induced response resulted in $\mathrm{pIC}_{50}$ values of $5.07 \pm 0.03,5.24 \pm 0.03$, Aceta, Imida, Cloth and Thiac, respectively. No $\mathrm{pIC}_{50}$ values could be determined for Thiam and Dino. Note the treatment scheme (lower left corner), illustrating the experimental design. Detailed data on n numbers are found in table S6 on the responses stimulated by ABT 594. c The concentration$5.05 \pm 0.05$ and $5.08 \pm 0.06$ for
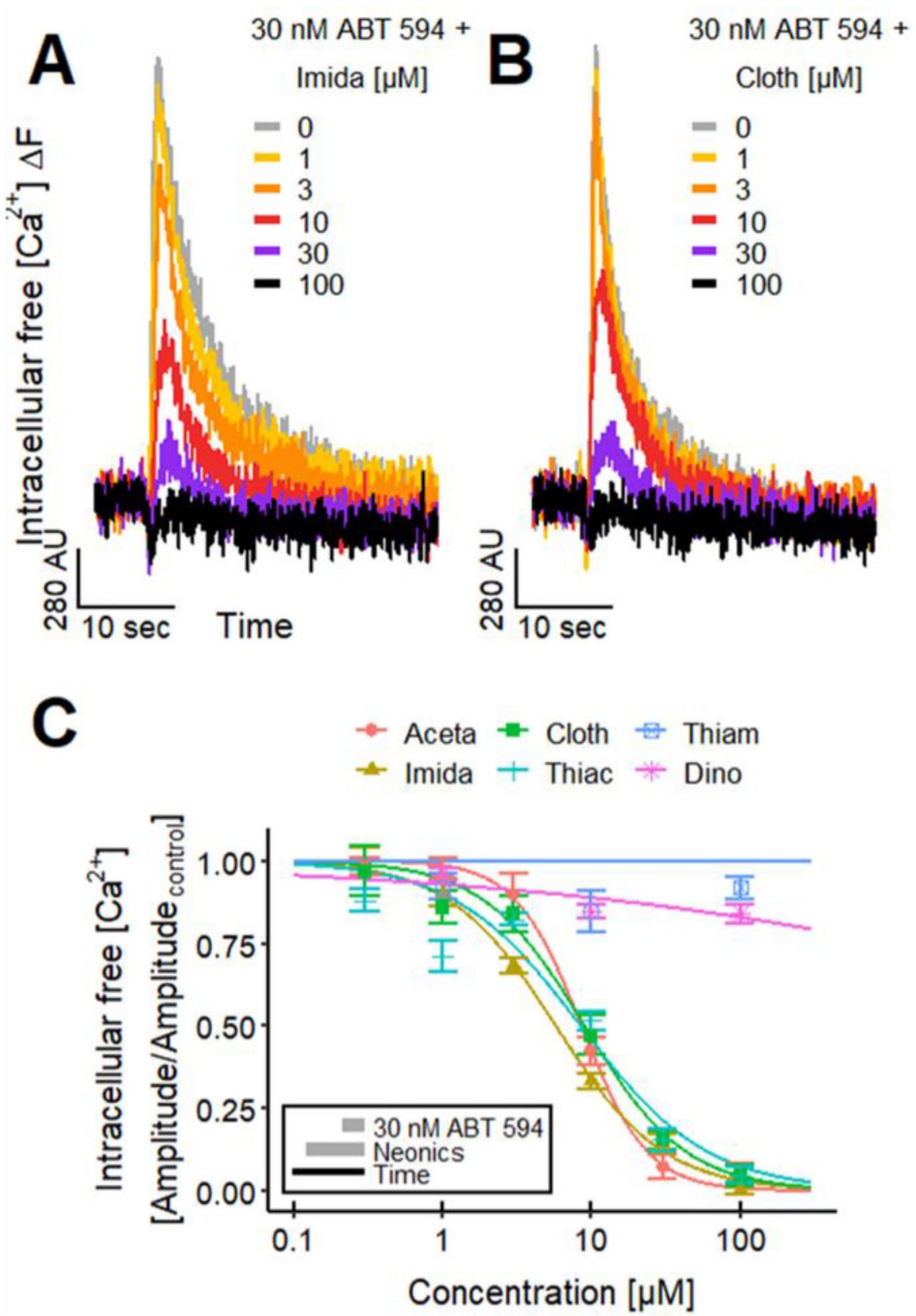

exceeding the ARfD is predicted to lead to concentrations that may be sufficient to affect $\mathrm{nAChR}$ signaling.

\section{Conclusions and outlook}

In the present study, we investigated the functional expression and impact of $n A C h R s$ on $\left[\mathrm{Ca}^{2+}\right]_{i}$ in two well-established model systems for dopaminergic human neurons. Based on this characterization, we asked whether the most widely used neonicotinoids (Jeschke et al. 2011; Bass et al. 2015) affected human nAChRs, in addition to their known action on insect receptors (Brown et al. 2006; Tan et al. 2007). We provided here compelling evidence for the triggering of cholinergic signal transduction by the neonicotinoid pesticides Aceta, Imida, Cloth and Thiac. Thus, our study is in line with earlier findings obtained with other mammalian cells, i.e., primary rat brain cultures (KimuraKuroda et al. 2012), and it provides clear evidence for a potential human hazard of such compounds.

Many subtypes of nAChRs are expressed in dopaminergic neurons, where they modulate the electrical activity and the release of dopamine (Rapier et al. 1988; Grady et al. 1992; Quik and Kulak 2002; Mameli-Engvall et al. 2006; 
Quik and Wonnacott 2011; de Kloet et al. 2015). As the nicotinic signaling thereby affects the functioning, plasticity and development of the dopaminergic nervous system, it is of crucial importance to learn about a potential effect of neonicotinoids in neurons and to determine the risk potential for the dopaminergic system or other important circuits of the brain (Stevens et al. 2003; Wheeler and Cooper 2004; Welsby et al. 2006; Slotkin et al. 2006; Ziviani et al. 2011; Miwa et al. 2011; Lozada et al. 2012; Romoli et al. 2019). While our study provides unambiguous evidence for the agonist role of some neonicotinoids on human nAChRs, followup studies will be required to judge the full toxicological implication of our findings. We provide here some initial conclusions and highlight important gaps of knowledge to be addressed.

Concerning the toxicant-target interaction (also termed molecular initiating event, using the terminology of adverse outcome pathways), two findings are remarkable. First, it is clear from a broad range of data provided, that various subtypes of nAChR may be activated by neonicotinoids. We provide here evidence for a role of both $\alpha 7$ and non- $\alpha 7$ receptors. This is consistent with binding experiments and functional studies based on ${ }^{86} \mathrm{Rb}^{+}$-flux, all of which demonstrated the interaction of, e.g., Imida or Aceta with various receptor types (Tomizawa and Casida 1999, 2005). Notably, the available literature data on the potencies of Imida and Aceta have a wide spread $(0.7-320 \mu \mathrm{M}$, depending on the assessment method). Our data on a physiological signaling response (change of $\left[\mathrm{Ca}^{2+}\right]_{i}$ ) provide important information on toxicologically important concentration ranges. Our data on direct stimulation of naive cells by neonicotinoids suggest that the lowest concentrations eliciting a neuronal response are in the $10 \mu \mathrm{M}$ range. However, it needs to be considered that $\left[\mathrm{Ca}^{2+}\right]_{\mathrm{i}}$ signaling effects in our model systems may be masked by extremely rapid receptor desensitization. Prevention of tachyphylaxis, combined with allosteric enhancement by the modulator PNU, allowed Aceta, Imida, Cloth and Thiac to be detected in SH-SY5Y cells at concentrations of $\geq 1 \mu \mathrm{M}$. This potency range is fully consistent with data from a desensitization assay in LUHMES cells, where the functional consequence of neonicotinoid exposure on subsequent cholinergic signaling was investigated. In addition, in this setup, compound activity started to be detected in the very low micromolar range for all four active compounds. Notably, the desensitizing aspect may be equally problematic for neurodevelopment as a potential overstimulation. To use such data for in vitro-to-in vivo extrapolations and as point-of-departure for risk assessment, the corresponding free toxicant concentrations need to be known: biokinetics calculations applied to our cell models showed that the free drug concentration was very close (mostly $<1 \%$ deviation) to the nominal concentration (Table S10).
The second important aspect of target interaction is our observation of two distinct subgroups of neonicotinoids with respect to neuronal signaling. While four test compounds showed relatively similar effects and effect potencies, two other agents (Thiam, Dino) were inactive within the test range (i.e., at least $100 \times$ less potent). The activity differences correlated well with favored docking poses of the ligands in a molecular model of the nAChR. While this will need further elucidation on the level of receptor binding and other molecular pharmacology approaches, this clear subgrouping suggests a high specificity of the LUHMES assay.

Whether the signaling disturbances measured here have lasting neurofunctional effects needs to be studied further. However, many studies on other nicotinic agonists (including nicotine) suggest that compounds triggering $\mathrm{nAChR}$ will affect the nervous system function not only acutely, but also affect its plasticity and development (Wheeler and Cooper 2004; Slotkin et al. 2006; Ziviani et al. 2011; Lozada et al. 2012; Romoli et al. 2019). One study in rat neurons also shows that Aceta/Imida may alter the gene expression of neurons upon prolonged exposure (Kimura-Kuroda et al. 2016). Concerning human data, four studies on chronic effects of neonicotinoids have been reported (Cimino et al. 2017). In all of them, some significant general developmen$\mathrm{tal} /$ neurological effects were observed when the population was stratified according to urine biomarkers, proximity to agricultural production or to use of neonicotinoid-containing anti-tick sprays.

A more difficult question is whether neonicotinoids have the potential to affect the development of the fetal brain (EFSA Panel on Plant Protection Products and their Residues (PPR) 2013) and thus trigger developmental neurotoxicity (DNT). Many other compounds that trigger alterations in neurotransmitter signaling, but no overt structural defects have been shown to trigger DNT. They include for instance MDMA, heroine (Aschner et al. 2017) and nicotine itself (Slikker Jr et al. 2005; Dwyer et al. 2009; Slotkin et al. 2016). Moreover, compounds that hardly affect the adult brain (in typical exposure situations) have been shown to affect the developing brain with late life consequences of fetal exposure. Well-documented examples are methylmercury and lead (Grandjean and Landrigan 2014). These examples from other compounds make it plausible that neonicotinoids pose a DNT hazard, but direct evidence is quite limited at present. As is good practice in toxicology, each individual compound needs to be evaluated for its proper effect/hazard. A transfer of knowledge and conclusions from one compound (e.g., nicotine) to others (neonicotinoids) always bears uncertainties (Rovida et al. 2020). More definite data on individual neonicotinoids are required in the future to confirm or disprove the DNT alert triggered by our study. 
For a full risk assessment, some additional aspects need to be addressed. First, the molecular structure-activity relationship will require new technical approaches. Receptors with defined subunit stoichiometry may be expressed in Xenopus laevis oocytes to clearly identify the molecular targets of active neonicotinoids and to verify that the inactive ones do not interact with any of the receptors. Second, metabolism and metabolites will require additional attention. In general, neonicotinoids have relatively long half-lives, and we have provided data on the direct activity of parent compounds. However, there may be also some active metabolites. Several studies showed that the Imida metabolite desnitro-imidacloprid exhibits higher potency at inhibiting the binding of $\left[{ }^{3} \mathrm{H}\right]$ nicotine or $\left[{ }^{125} \mathrm{I}\right] \alpha-\mathrm{BGT}$ to mammalian nAChRs compared to its precursor Imida, but similar to nicotine (Chao and Casida 1997; Tomizawa and Casida 1999; D'Amour and Casida 1999; Tomizawa et al. 2000). The same finding has also been reported for chicken $\alpha 4 \beta 2$ nAChR expressed in M10 cells (Tomizawa and Casida 2000). Thus, generation of toxicokinetics data on this metabolite together with bioactivity measurements on human neurons will be interesting. Third, PBTK models for all compounds will need to be applied to different exposure scenarios. A model validation with human data would be desirable to show reliability of the data and predictions from these models. Previous attempts into this direction have used microdosing in volunteers with deuterium-labeled compounds (Harada et al. 2016). Concerning the question of neurological consequences, controlled short-term experiments with volunteers have been performed to study effects of nicotine (Grundey et al. 2018). Whether such studies would be ethically acceptable for pesticides is doubtful for most countries in Europe.

Supplementary Information The online version contains supplementary material available at https://doi.org/10.1007/s00204-021-03031-1.

Acknowledgements This work was supported by the BMBF, the InViTe PhD program from the Baden-Wuerttemberg Ministry for Science, Research and Art (MWK Baden-Württemberg), EFSA, the DK-EPA (MST-667-00205), the Swedish Research Council (VR2018-03269), the University of Konstanz and Stockholm University. It has received funding from the European Union's ERASMUS+ programme and the Horizon 2020 research and innovation programme under grant agreements no. 681002 (EU-ToxRisk) and no. 825759 (ENDpoiNTs). This work received financial support from the State Ministry of Baden-Wuerttemberg for Economic Affairs, Labour and Housing Construction.

Author contributions DL: conceived or designed the study, performed the research, analyzed the data and wrote the paper. MH, JS, YJ, and IS: performed the research and analyzed the data. JB and MB: performed the research, analyzed the data and wrote the paper. TD, CM, IG, KG, and GE: contributed new methods or models and analyzed the data. SB, $\mathrm{AF}, \mathrm{ML}$, and $\mathrm{UK}$ : conceived or designed the study and wrote the paper.
Funding Open Access funding enabled and organized by Projekt DEAL.

\section{Declarations}

Conflict of interest The authors declare no conflict of interest.

Open Access This article is licensed under a Creative Commons Attribution 4.0 International License, which permits use, sharing, adaptation, distribution and reproduction in any medium or format, as long as you give appropriate credit to the original author(s) and the source, provide a link to the Creative Commons licence, and indicate if changes were made. The images or other third party material in this article are included in the article's Creative Commons licence, unless indicated otherwise in a credit line to the material. If material is not included in the article's Creative Commons licence and your intended use is not permitted by statutory regulation or exceeds the permitted use, you will need to obtain permission directly from the copyright holder. To view a copy of this licence, visit http://creativecommons.org/licenses/by/4.0/.

\section{References}

Abou-Donia MB, Goldstein LB, Bullman S et al (2008) Imidacloprid induces neurobehavioral deficits and increases expression of glial fibrillary acidic protein in the motor cortex and hippocampus in offspring rats following in utero exposure. J Toxicol Environ Health A 71:119-130. https://doi.org/10.1080/1528739070 1613140

Agrawal L, Vimal SK, Shiga T (2019) Role of serotonin 4 receptor in the growth of hippocampal neurons during the embryonic development in mice. Neuropharmacology 158:107712. https://doi. org/10.1016/j.neuropharm.2019.107712

Alijevic O, McHugh D, Rufener L et al (2020) An electrophysiological characterization of naturally occurring tobacco alkaloids and their action on human $\alpha 4 \beta 2$ and $\alpha 7$ nicotinic acetylcholine receptors. Phytochemistry 170:112187. https://doi.org/10.1016/j.phyto chem.2019.112187

Alkondon M, Pereira EFR, Eisenberg HM, Albuquerque EX (1999) Choline and selective antagonists identify two subtypes of nicotinic acetylcholine receptors that modulate GABA release from CA1 interneurons in rat hippocampal slices. J Neurosci 19:26932705. https://doi.org/10.1523/JNEUROSCI.19-07-02693.1999

Arias HR, Feuerbach D, Targowska-Duda K et al (2015) Pharmacological and molecular studies on the interaction of varenicline with different nicotinic acetylcholine receptor subtypes. Potential mechanism underlying partial agonism at human $\alpha 4 \beta 2$ and $\alpha 3 \beta 4$ subtypes. Biochim Biophys Acta BBA Biomembr 1848:731-741. https://doi.org/10.1016/j.bbamem.2014.11.003

Armstrong LC, Kirsch GE, Fedorov NB et al (2017) High-throughput patch clamp screening in human $\alpha 6$-containing nicotinic acetylcholine receptors. SLAS Discov Adv Sci Drug Discov 22:686695. https://doi.org/10.1177/2472555217696794

Aschner M, Ceccatelli S, Daneshian M et al (2017) Reference compounds for alternative test methods to indicate developmental neurotoxicity (DNT) potential of chemicals: example lists and criteria for their selection and use. Altex 34:49-74. https://doi. org/10.14573/altex.1604201

Attali D (2020) shinyjs: easily improve the user experience of your shiny apps in seconds. R package version 1.1. https://CRAN.Rproject.org $/$ package $=$ shinyjs 
Attoff K, Kertika D, Lundqvist J et al (2016) Acrylamide affects proliferation and differentiation of the neural progenitor cell line C17.2 and the neuroblastoma cell line SH-SY5Y. Toxicol In Vitro 35:100-111. https://doi.org/10.1016/j.tiv.2016.05.014

Attoff K, Johansson Y, Cediel-Ulloa A et al (2020) Acrylamide alters CREB and retinoic acid signalling pathways during differentiation of the human neuroblastoma SH-SY5Y cell line. Sci Rep 10:16714. https://doi.org/10.1038/s41598-020-73698-6

Bache SM, Wickham H (2014) magrittr: a forward-pipe operator for R. R package version 1.5. https://CRAN.R-project.org/package= magrittr

Bass C, Denholm I, Williamson MS, Nauen R (2015) The global status of insect resistance to neonicotinoid insecticides. Pestic Biochem Physiol 121:78-87. https://doi.org/10.1016/j.pestbp.2015.04.004

Benallegue N, Mazzaferro S, Alcaino C, Bermudez I (2013) The additional ACh binding site at the $\alpha 4(+) / \alpha 4(-)$ interface of the $(\alpha 4 \beta 2) 2 \alpha 4$ nicotinic ACh receptor contributes to desensitization. Br J Pharmacol 170:304-316. https://doi.org/10.1111/bph.12268

Bengtsson H (2020) matrixStats: functions that apply to rows and columns of matrices (and to vectors). R package version 0.56.0. https://CRAN.R-project.org/package $=$ matrixStats

Berheim EH, Jenks JA, Lundgren JG et al (2019) Effects of neonicotinoid insecticides on physiology and reproductive characteristics of captive female and fawn white-tailed deer. Sci Rep 9:4534. https://doi.org/10.1038/s41598-019-40994-9

Berman HM, Westbrook J, Feng Z et al (2000) The protein data bank. Nucleic Acids Res 28:235-242. https://doi.org/10.1093/nar/28.1. 235

Bermudez I, Moroni M (2006) Phosphorylation and function of $\alpha 4 \beta 2$ receptor. J Mol Neurosci 30:97-98. https://doi.org/10.1385/JMN: 30:1:97

Bianchi BR, Lynch KJ, Touma E et al (1999) Pharmacological characterization of recombinant human and rat $\mathrm{P} 2 \mathrm{X}$ receptor subtypes. Eur J Pharmacol 376:127-138. https://doi.org/10.1016/S00142999(99)00350-7

Brown LA, Ihara M, Buckingham SD et al (2006) Neonicotinoid insecticides display partial and super agonist actions on native insect nicotinic acetylcholine receptors. J Neurochem 99:608-615. https://doi.org/10.1111/j.1471-4159.2006.04084.x

Brüll M, Spreng A-S, Gutbier S et al (2020) Incorporation of stem cellderived astrocytes into neuronal organoids to allow neuro-glial interactions in toxicological studies. ALTEX Altern Anim Exp. https://doi.org/10.14573/altex.1911111

Buisson B, Gopalakrishnan M, Arneric SP et al (1996) Human $\alpha 4 \beta 2$ neuronal nicotinic acetylcholine receptor in HEK 293 cells: a patch-clamp study. J Neurosci 16:7880-7891. https://doi.org/10. 1523/JNEUROSCI.16-24-07880.1996

Burke AP, Niibori Y, Terayama H et al (2018) Mammalian susceptibility to a neonicotinoid insecticide after fetal and early postnatal exposure. Sci Rep 8:16639. https://doi.org/10.1038/ s41598-018-35129-5

Campling BG, Kuryatov A, Lindstrom J (2013) Acute activation, desensitization and smoldering activation of human acetylcholine receptors. PLoS ONE 8:e79653. https://doi.org/10.1371/journal. pone.0079653

Capelli AM, Castelletti L, Chen YH et al (2011) Stable expression and functional characterization of a human nicotinic acetylcholine receptor with $\alpha 6 \beta 2$ properties: discovery of selective antagonists. Br J Pharmacol 163:313-329. https://doi.org/10.1111/j. 1476-5381.2011.01213.x

Carbone A-L, Moroni M, Groot-Kormelink P-J, Bermudez I (2009) Pentameric concatenated (a4)2(b2)3 and (a4)3(b2)2 nicotinic acetylcholine receptors: subunit arrangement determines functional expression. Br J Pharmacol 156:970-981. https://doi.org/ 10.1111/j.1476-5381.2008.00104.x
Cartereau A, Martin C, Thany SH (2018) Neonicotinoid insecticides differently modulate acetycholine-induced currents on mammalian $\alpha 7$ nicotinic acetylcholine receptors. Br J Pharmacol 175:1987-1998. https://doi.org/10.1111/bph.14018

Casida JE (2018) Neonicotinoids and other insect nicotinic receptor competitive modulators: progress and prospects. Annu Rev Entomol 63:125-144. https://doi.org/10.1146/annur ev-ento-020117-043042

Casida JE, Durkin KA (2013) Neuroactive insecticides: targets, selectivity, resistance, and secondary effects. Annu Rev Entomol 58:99-117. https://doi.org/10.1146/annurev-ento-120811-153645

Chang W, Cheng J, Allaire J, et al (2020) shiny: web application framework for R. R package version 1.4.0.2. https://CRAN.R-project. org/package $=$ shiny

Chao SL, Casida JE (1997) Interaction of imidacloprid metabolites and analogs with the nicotinic acetylcholine receptor of mouse brain in relation to toxicity. Pestic Biochem Physiol 58:77-88. https:// doi.org/10.1006/pest.1997.2284

Chatterjee S, Steensland P, Simms JA et al (2011) Partial agonists of the $\alpha 3 \beta 4 *$ neuronal nicotinic acetylcholine receptor reduce ethanol consumption and seeking in rats. Neuropsychopharmacology 36:603-615. https://doi.org/10.1038/npp.2010.191

Chatzidaki A, Fouillet A, Li J et al (2015) Pharmacological characterisation of nicotinic acetylcholine receptors expressed in human iPSC-derived neurons. PLoS ONE. https://doi.org/10.1371/journ al.pone. 0125116

Chavez-Noriega LE, Gillespie A, Stauderman KA et al (2000) Characterization of the recombinant human neuronal nicotinic acetylcholine receptors $\alpha 3 \beta 2$ and $\alpha 4 \beta 2$ stably expressed in HEK293 cells. Neuropharmacology 39:2543-2560. https://doi.org/10. 1016/S0028-3908(00)00134-9

Cheng J (2018) miniUI: shiny UI widgets for small screens. R package version 0.1.1.1. https://CRAN.R-project.org/package $=$ miniUI

Chen D, Gao F, Ma X et al (2018) Pharmacological and functional comparisons of $\alpha 6 / \alpha 3 \beta 2 \beta 3$-nAChRs and $\alpha 4 \beta 2$-nAChRs heterologously expressed in the human epithelial SH-EP1 cell line. Acta Pharmacol Sin 39:1571-1581. https://doi.org/10.1038/aps. 2017.209

Cimino AM, Boyles AL, Thayer KA, Perry MJ (2017) Effects of neonicotinoid pesticide exposure on human health: a systematic review. Environ Health Perspect 125:155-162. https://doi.org/ 10.1289/EHP515

Coe JW, Brooks PR, Vetelino MG et al (2005) Varenicline: an $\alpha 4 \beta 2$ nicotinic receptor partial agonist for smoking cessation. J Med Chem 48:3474-3477. https://doi.org/10.1021/jm050069n

Cummins TR, Rush AM, Estacion M et al (2009) Voltage-clamp and current-clamp recordings from mammalian DRG neurons. Nat Protoc 4:1103-1112. https://doi.org/10.1038/nprot.2009.91

D'Amour KA, Casida JE (1999) Desnitroimidacloprid and nicotine binding site in rat recombinant $\alpha 4 \beta 2$ neuronal nicotinic acetylcholine receptor. Pestic Biochem Physiol 64:55-61. https://doi. org/10.1006/pest.1999.2409

Danker T (2018) ephys2: read, analyze and plot HEKA Patchmaster files. R package version 0.12.0. https://github.com/tdanker/ ephys2

Davies M, Nowotka M, Papadatos G et al (2015) ChEMBL web services: streamlining access to drug discovery data and utilities. Nucleic Acids Res 43:W612-W620. https://doi.org/10.1093/nar/ gkv352

de Kloet SF, Mansvelder HD, De Vries TJ (2015) Cholinergic modulation of dopamine pathways through nicotinic acetylcholine receptors. Biochem Pharmacol 97:425-438. https://doi.org/10.1016/j. bcp.2015.07.014

Delp J, Gutbier S, Cerff M et al (2018a) Stage-specific metabolic features of differentiating neurons: implications for toxicant 
sensitivity. Toxicol Appl Pharmacol 354:64-80. https://doi.org/ 10.1016/j.taap.2017.12.013

Delp J, Gutbier S, Klima S et al (2018b) A high-throughput approach to identify specific neurotoxicants/developmental toxicants in human neuronal cell function assays. Altex 35:235-253. https:// doi.org/10.14573/altex.1712182

Delp J, Funke M, Rudolf F et al (2019) Development of a neurotoxicity assay that is tuned to detect mitochondrial toxicants. Arch Toxicol 93:1585-1608. https://doi.org/10.1007/s00204-019-02473-y

Delp J, Cediel-Ulloa A, Suciu I et al (2021) Neurotoxicity and underlying cellular changes of 21 mitochondrial respiratory chain inhibitors. Arch Toxicol 95:591-615. https://doi.org/10.1007/ s00204-020-02970-5

Dickinson JA, Hanrott KE, Mok MHS et al (2007) Differential coupling of $\alpha 7$ and non- $\alpha 7$ nicotinic acetylcholine receptors to calciuminduced calcium release and voltage-operated calcium channels in PC12 cells. J Neurochem 100:1089-1096. https://doi.org/10. 1111/j.1471-4159.2006.04273.x

Donnelly-Roberts DL, Puttfarcken PS, Kuntzweiler TA et al (1998) ABT-594 [(R)-5-(2-Azetidinylmethoxy)-2-chloropyridine]: a novel, orally effective analgesic acting via neuronal nicotinic acetylcholine receptors: I. In VitroCharacterization. J Pharmacol Exp Ther 285:777-786

Duzguner V, Erdogan S (2012) Chronic exposure to imidacloprid induces inflammation and oxidative stress in the liver \& central nervous system of rats. Pestic Biochem Physiol 104:58-64. https://doi.org/10.1016/j.pestbp.2012.06.011

Dwyer JB, McQuown SC, Leslie FM (2009) The dynamic effects of nicotine on the developing brain. Pharmacol Ther 122:125139. https://doi.org/10.1016/j.pharmthera.2009.02.003

Eaton JB, Lucero LM, Stratton $H$ et al (2014) The unique $\alpha 4(+) /(-)$ $\alpha 4$ agonist binding site in $(\alpha 4) 3(\beta 2) 2$ subtype nicotinic acetylcholine receptors permits differential agonist desensitization pharmacology versus the $(\alpha 4) 2(\beta 2) 3$ Subtype. J Pharmacol Exp Ther 348:46-58. https://doi.org/10.1124/jpet.113.208389

Edwards SM (2019) lemon: Freshing Up your "ggplot2" Plots. R package version 0.4.3. https://CRAN.R-project.org/package= lemon

EFSA Panel on Plant Protection Products and their Residues (PPR) (2013) Scientific opinion on the developmental neurotoxicity potential of acetamiprid and imidacloprid. EFSA J 11:3471. https://doi.org/10.2903/j.efsa.2013.3471

Elliott KJ, Ellis SB, Berckhan KJ et al (1996) Comparative structure of human neuronal $\alpha 2-\alpha 7$ and $\beta 2-\beta 4$ nicotinic acetylcholine receptor subunits and functional expression of the $\alpha 2, \alpha 3, \alpha 4, \alpha 7, \beta 2$, and $\beta 4$ subunits. J Mol Neurosci 7:217-228. https://doi.org/10. 1007/BF02736842

Ertl P, Rohde B, Selzer P (2000) Fast calculation of molecular polar surface area as a sum of fragment-based contributions and its application to the prediction of drug transport properties. J Med Chem 43:3714-3717. https://doi.org/10.1021/jm000942e

Fenster CP, Rains MF, Noerager B et al (1997) Influence of subunit composition on desensitization of neuronal acetylcholine receptors at low concentrations of nicotine. J Neurosci 17:5747-5759. https://doi.org/10.1523/JNEUROSCI.17-15-05747.1997

Fitch RW, Xiao Y, Kellar KJ, Daly JW (2003) Membrane potential fluorescence: a rapid and highly sensitive assay for nicotinic receptor channel function. Proc Natl Acad Sci 100:4909-4914. https://doi. org/10.1073/pnas.0630641100

Ford KA, Casida JE (2006) Chloropyridinyl neonicotinoid insecticides: diverse molecular substituents contribute to facile metabolism in mice. Chem Res Toxicol 19:944-951. https://doi.org/10.1021/ tx0600696

Fritsche E, Grandjean P, Crofton KM et al (2018) Consensus statement on the need for innovation, transition and implementation of developmental neurotoxicity (DNT) testing for regulatory purposes. Toxicol Appl Pharmacol 354:3-6. https://doi.org/10. 1016/j.taap.2018.02.004

Fucile S (2004) Ca2+ permeability of nicotinic acetylcholine receptors. Cell Calcium 35:1-8. https://doi.org/10.1016/j.ceca.2003.08.006

Gibbons D, Morrissey C, Mineau P (2015) A review of the direct and indirect effects of neonicotinoids and fipronil on vertebrate wildlife. Environ Sci Pollut Res 22:103-118. https://doi.org/10.1007/ s11356-014-3180-5

Gill JK, Chatzidaki A, Ursu D et al (2013) Contrasting properties of $\alpha 7$-selective orthosteric and allosteric agonists examined on native nicotinic acetylcholine receptors. PLoS ONE 8:e55047. https://doi.org/10.1371/journal.pone.0055047

Gopalakrishnan M, Buisson B, Touma E et al (1995) Stable expression and pharmacological properties of the human $\alpha 7$ nicotinic acetylcholine receptor. Eur J Pharmacol Mol Pharmacol 290:237-246. https://doi.org/10.1016/0922-4106(95)00083-6

Gotti C, Carbonnelle E, Moretti M et al (2000) Drugs selective for nicotinic receptor subtypes: a real possibility or a dream? Behav Brain Res 113:183-192. https://doi.org/10.1016/S0166-4328(00) 00212-6

Gotti C, Zoli M, Clementi F (2006) Brain nicotinic acetylcholine receptors: native subtypes and their relevance. Trends Pharmacol Sci 27:482-491. https://doi.org/10.1016/j.tips.2006.07.004

Gould J, Reeve HL, Vaughan PFT, Peers C (1992) Nicotinic acetylcholine receptors in human neuroblastoma (SH-SY5Y) cells. Neurosci Lett 145:201-204. https://doi.org/10.1016/0304-3940(92) 90022-Y

Goulson D (2013) REVIEW: an overview of the environmental risks posed by neonicotinoid insecticides. J Appl Ecol 50:977-987. https://doi.org/10.1111/1365-2664.12111

Grady S, Marks MJ, Wonnacott S, Collins AC (1992) Characterization of nicotinic receptor-mediated $\left[{ }^{3} \mathrm{H}\right]$ dopamine release from synaptosomes prepared from mouse striatum. J Neurochem 59:848-856. https://doi.org/10.1111/j.1471-4159.1992.tb08322.x

Grandjean P, Landrigan P (2006) Developmental neurotoxicity of industrial chemicals. Lancet 368:2167-2178. https://doi.org/10. 1016/S0140-6736(06)69665-7

Grandjean P, Landrigan PJ (2014) Neurobehavioural effects of developmental toxicity. Lancet Neurol 13:330-338. https://doi.org/10. 1016/S1474-4422(13)70278-3

Gray R, Rajan AS, Radcliffe KA et al (1996) Hippocampal synaptic transmission enhanced by low concentrations of nicotine. Nature 383:713-716. https://doi.org/10.1038/383713a0

Grønlien JH, Håkerud M, Ween H et al (2007) Distinct profiles of $\alpha 7$ nAChR positive allosteric modulation revealed by structurally diverse chemotypes. Mol Pharmacol 72:715-724. https://doi.org/ 10.1124/mol.107.035410

Grothendieck G, Kates L, Petzoldt T (2016) proto: Prototype ObjectBased Programming. R package version 1.0.0. https://CRAN.Rproject.org $/$ package $=$ proto

Grundey J, Barlay J, Batsikadze G et al (2018) Nicotine modulates human brain plasticity via calcium-dependent mechanisms. J Physiol 596:5429-5441. https://doi.org/10.1113/JP276502

Grunwald L-M, Stock R, Haag K et al (2019) Comparative characterization of human induced pluripotent stem cells (hiPSC) derived from patients with schizophrenia and autism. Transl Psychiatry 9:179. https://doi.org/10.1038/s41398-019-0517-3

Gustafsson H, Runesson J, Lundqvist J et al (2010) Neurofunctional endpoints assessed in human neuroblastoma SH-SY5Y cells for estimation of acute systemic toxicity. Toxicol Appl Pharmacol 245:191-202. https://doi.org/10.1016/j.taap.2010.02.018

Hamill OP, Marty A, Neher E et al (1981) Improved patch-clamp techniques for high-resolution current recording from cells and cellfree membrane patches. Pflüg Arch 391:85-100. https://doi.org/ 10.1007/BF00656997 
Harada KH, Tanaka K, Sakamoto H et al (2016) Biological monitoring of human exposure to neonicotinoids using urine samples, and neonicotinoid excretion kinetics. PLoS ONE 11:e0146335. https://doi.org/10.1371/journal.pone.0146335

Harder E, Damm W, Maple J et al (2016) OPLS3: a force field providing broad coverage of drug-like small molecules and proteins. J Chem Theory Comput 12:281-296. https://doi.org/10.1021/acs. jctc.5b00864

Harpsøe K, Ahring PK, Christensen JK et al (2011) Unraveling the high- and low-sensitivity agonist responses of nicotinic acetylcholine receptors. J Neurosci 31:10759-10766. https://doi.org/ 10.1523/JNEUROSCI.1509-11.2011

Harris G, Hogberg H, Hartung T, Smirnova L (2017) 3D differentiation of LUHMES cell line to study recovery and delayed neurotoxic effects. Curr Protoc Toxicol 73:11.23.1-11.23.28. https://doi.org/ $10.1002 /$ cptx.29

Hothorn T, Bretz F, Westfall P (2008) Simultaneous inference in general parametric models. Biom J 50:346-363. https://doi.org/10. 1002/bimj.200810425

House JS, Grimm FA, Jima DD et al (2017) A pipeline for highthroughput concentration response modeling of gene expression for toxicogenomics. Front Genet 8:168. https://doi.org/10. 3389/fgene.2017.00168

Hurst RS, Hajós M, Raggenbass M et al (2005) A novel positive allosteric modulator of the $\alpha 7$ neuronal nicotinic acetylcholine receptor. In vitro and in vivo characterization. J Neurosci 25:4396-4405. https://doi.org/10.1523/JNEUROSCI.5269-04. 2005

Ihara M, Matsuda K, Otake M et al (2003) Diverse actions of neonicotinoids on chicken $\alpha 7, \alpha 4 \beta 2$ and Drosophila-chicken SAD $\beta 2$ and ALS $\beta 2$ hybrid nicotinic acetylcholine receptors expressed in Xenopus laevis oocytes. Neuropharmacology 45:133-144. https://doi.org/10.1016/S0028-3908(03)00134-5

Ihara M, Okajima T, Yamashita A et al (2008) Crystal structures of Lymnaea stagnalis AChBP in complex with neonicotinoid insecticides imidacloprid and clothianidin. Invert Neurosci 8:71-81. https://doi.org/10.1007/s10158-008-0069-3

Jeschke P, Nauen R, Schindler M, Elbert A (2011) Overview of the status and global strategy for neonicotinoids. J Agric Food Chem 59:2897-2908. https://doi.org/10.1021/jf101303g

Jonsson M, Gurley D, Dabrowski M et al (2006) Distinct pharmacologic properties of neuromuscular blocking agents on human neuronal nicotinic acetylcholine receptors: a possible explanation for the train-of-four fade. Anesthesiology 105:521-533

Kang Y, Kitai ST (1993) A whole cell patch-clamp study on the pacemaker potential in dopaminergic neurons of rat substantia nigra compacta. Neurosci Res 18:209-221. https://doi.org/10. 1016/0168-0102(93)90056-V

Karreman C, Klima S, Holzer A-K, Leist M (2020) CaFFEE : A program for evaluating time courses of $\mathrm{Ca} 2+$ dependent signal changes of complex cells loaded with fluorescent indicator dyes. Altern Anim Exp ALTEX 37:332-336. https://doi.org/ 10.14573/altex.2003191

Khakh BS, North RA (2012) Neuromodulation by extracellular ATP and P2X receptors in the CNS. Neuron 76:51-69. https://doi. org/10.1016/j.neuron.2012.09.024

Kimura-Kuroda J, Komuta Y, Kuroda Y et al (2012) Nicotine-like effects of the neonicotinoid insecticides acetamiprid and imidacloprid on cerebellar neurons from neonatal rats. PLoS ONE 7:e32432. https://doi.org/10.1371/journal.pone.0032432

Kimura-Kuroda J, Nishito Y, Yanagisawa H et al (2016) Neonicotinoid insecticides alter the gene expression profile of neuronenriched cultures from neonatal rat cerebellum. Int J Environ Res Public Health. https://doi.org/10.3390/ijerph13100987

Krebs A, Nyffeler J, Karreman C et al (2020) Determination of benchmark concentrations and their statistical uncertainty for cytotoxicity test data and functional in vitro assays. ALTEX Altern Anim Exp 37:155-163. https://doi.org/10.14573/altex. 1912021

Kriegstein AR (2005) Constructing circuits: neurogenesis and migration in the developing neocortex. Epilepsia 46:15-21. https://doi. org/10.1111/j.1528-1167.2005.00304.x

Krug AK, Balmer NV, Matt F et al (2013) Evaluation of a human neurite growth assay as specific screen for developmental neurotoxicants. Arch Toxicol 87:2215-2231. https://doi.org/10.1007/ s00204-013-1072-y

Krug AK, Gutbier S, Zhao L et al (2014) Transcriptional and metabolic adaptation of human neurons to the mitochondrial toxicant MPP +. Cell Death Dis 5:e1222-e1222. https://doi.org/10.1038/cddis. 2014.166

Kuryatov A, Gerzanich V, Nelson M et al (1997) Mutation causing autosomal dominant nocturnal frontal lobe epilepsy alters $\mathrm{Ca} 2+$ permeability, conductance, and gating of human $\alpha 4 \beta 2$ nicotinic acetylcholine receptors. J Neurosci 17:9035-9047. https://doi. org/10.1523/JNEUROSCI.17-23-09035.1997

Kwon H-B, Sabatini BL (2011) Glutamate induces de novo growth of functional spines in developing cortex. Nature 474:100-104. https://doi.org/10.1038/nature09986

Larsen HM, Hansen SK, Mikkelsen JD et al (2019) Alpha7 nicotinic acetylcholine receptors and neural network synaptic transmission in human induced pluripotent stem cell-derived neurons. Stem Cell Res 41:101642. https://doi.org/10.1016/j.scr.2019.101642

Leist M, Nicotera P (1998) Calcium and neuronal death. Reviews of physiology biochemistry and pharmacology, vol 132. Springer, Berlin, pp 79-125

Lemon J (2006) Plotrix: a package in the red light district of R. R-News $6: 8-12$

LeSage MG, Gustaf E, Dufek MB, Pentel PR (2006) Effects of maternal intravenous nicotine administration on locomotor behavior in pre-weanling rats. Pharmacol Biochem Behav 85:575-583. https://doi.org/10.1016/j.pbb.2006.10.012

Lester RAJ (2004) Activation and desensitization of heteromeric neuronal nicotinic receptors: implications for non-synaptic transmission. Bioorg Med Chem Lett 14:1897-1900. https://doi.org/10. 1016/j.bmcl.2004.02.081

Levin ED, Briggs SJ, Christopher NC, Rose JE (1993) Prenatal nicotine exposure and cognitive performance in rats. Neurotoxicol Teratol 15:251-260. https://doi.org/10.1016/0892-0362(93)90006-A

Levin ED, McClernon FJ, Rezvani AH (2006) Nicotinic effects on cognitive function: behavioral characterization, pharmacological specification, and anatomic localization. Psychopharmacology 184:523-539. https://doi.org/10.1007/s00213-005-0164-7

Li S, Kumar TP, Joshee S et al (2018) Endothelial cell-derived GABA signaling modulates neuronal migration and postnatal behavior. Cell Res 28:221-248. https://doi.org/10.1038/cr.2017.135

Li AJ, Kannan K (2020) Profiles of urinary neonicotinoids and dialkylphosphates in populations in nine countries. Environ Int 145:106120. https://doi.org/10.1016/j.envint.2020.106120

Li AJ, Martinez-Moral M-P, Kannan K (2020) Variability in urinary neonicotinoid concentrations in single-spot and first-morning void and its association with oxidative stress markers. Environ Int 135:105415. https://doi.org/10.1016/j.envint.2019.105415

Lohren H, Blagojevic L, Fitkau R et al (2015) Toxicity of organic and inorganic mercury species in differentiated human neurons and human astrocytes. J Trace Elem Med Biol 32:200-208. https:// doi.org/10.1016/j.jtemb.2015.06.008

Loser D, Schaefer J, Danker T et al (2021) Human neuronal signaling and communication assays to assess functional neurotoxicity. Arch Toxicol 95:229-252. https://doi.org/10.1007/ s00204-020-02956-3 
Love MI, Huber W, Anders S (2014) Moderated estimation of fold change and dispersion for RNA-seq data with DESeq2. Genome Biol 15:550. https://doi.org/10.1186/s13059-014-0550-8

Lozada AF, Wang X, Gounko NV et al (2012) Glutamatergic synapse formation is promoted by $\alpha 7$-containing nicotinic acetylcholine receptors. J Neurosci 32:7651-7661. https://doi.org/10.1523/ JNEUROSCI.6246-11.2012

Lukas RJ, Norman SA, Lucero L (1993) Characterization of nicotinic acetylcholine receptors expressed by cells of the SH-SY5Y human neuroblastoma clonal line. Mol Cell Neurosci 4:1-12. https://doi.org/10.1006/mcne.1993.1001

Mameli-Engvall M, Evrard A, Pons S et al (2006) Hierarchical control of dopamine neuron-firing patterns by nicotinic receptors. Neuron 50:911-921. https://doi.org/10.1016/j.neuron.2006.05.007

Marfo JT, Fujioka K, Ikenaka Y et al (2015) Relationship between urinary $\mathrm{N}$-desmethyl-acetamiprid and typical symptoms including neurological findings: a prevalence case-control study. PLoS ONE 10:e0142172. https://doi.org/10.1371/journal.pone.01421 72

Marks MJ, Meinerz NM, Brown RWB, Collins AC (2010) 86Rb+ efflux mediated by $\alpha 4 \beta 2 *$-nicotinic acetylcholine receptors with high and low-sensitivity to stimulation by acetylcholine display similar agonist-induced desensitization. Biochem Pharmacol 80:1238-1251. https://doi.org/10.1016/j.bcp.2010.06.040

McGehee DS, Heath MJ, Gelber S et al (1995) Nicotine enhancement of fast excitatory synaptic transmission in CNS by presynaptic receptors. Science 269:1692-1696. https://doi.org/10.1126/scien ce. 7569895

Mendez D, Gaulton A, Bento AP et al (2019) ChEMBL: towards direct deposition of bioassay data. Nucleic Acids Res 47:D930-D940. https://doi.org/10.1093/nar/gky1075

Michelmore S, Croskery K, Nozulak J et al (2002) Study of the calcium dynamics of the human $\alpha 4 \beta 2, \alpha 3 \beta 4$ and $\alpha 1 \beta 1 \gamma \delta$ nicotinic acetylcholine receptors. Naunyn Schmiedebergs Arch Pharmacol 366:235-245. https://doi.org/10.1007/s00210-002-0589-z

Migliarini S, Pacini G, Pelosi B et al (2013) Lack of brain serotonin affects postnatal development and serotonergic neuronal circuitry formation. Mol Psychiatry 18:1106-1118. https://doi.org/10. 1038/mp.2012.128

Mihalak KB, Carroll IF, Luetje CW (2006) Varenicline is a partial agonist at $\alpha 4 \beta 2$ and a full agonist at $\alpha 7$ neuronal nicotinic receptors. Mol Pharmacol 70:801-805. https://doi.org/10.1124/mol. 106.025130

Mineur YS, Eibl C, Young G et al (2009) Cytisine-based nicotinic partial agonists as novel antidepressant compounds. J Pharmacol Exp Ther 329:377-386. https://doi.org/10.1124/jpet.108.149609

Miwa JM, Freedman R, Lester HA (2011) Neural systems governed by nicotinic acetylcholine receptors: emerging hypotheses. Neuron 70:20-33. https://doi.org/10.1016/j.neuron.2011.03.014

Mohamed F, Gawarammana I, Robertson TA et al (2009) Acute human self-poisoning with imidacloprid compound: a neonicotinoid insecticide. PLoS ONE 4:e5127. https://doi.org/10.1371/journ al.pone. 0005127

Molleman A (2003) Patch clamping: an introductory guide to patch clamp electrophysiology. Wiley, New York

Mousavi M, Hellström-Lindahl E (2009) Nicotinic receptor agonists and antagonists increase sAPP $\alpha$ secretion and decrease $\mathrm{A} \beta$ levels in vitro. Neurochem Int 54:237-244. https://doi.org/10.1016/j. neuint.2008.12.001

Mullen G, Napier J, Balestra M et al (2000) (-)-Spiro[1-azabicyclo[2.2.2] octane-3,5'-oxazolidin-2‘-one], a conformationally restricted analogue of acetylcholine, is a highly selective full agonist at the $\alpha 7$ nicotinic acetylcholine receptor. J Med Chem 43:4045-4050. https://doi.org/10.1021/jm000249r
Nelson ME, Kuryatov A, Choi CH et al (2003) Alternate stoichiometries of $\alpha 4 \beta 2$ nicotinic acetylcholine receptors. Mol Pharmacol 63:332-341. https://doi.org/10.1124/mol.63.2.332

Nguyen L, Rigo J-M, Rocher V et al (2001) Neurotransmitters as early signals for central nervous system development. Cell Tissue Res 305:187-202. https://doi.org/10.1007/s004410000343

$\mathrm{Ng}$ HJ, Whittemore ER, Tran MB et al (2007) Nootropic 7 nicotinic receptor allosteric modulator derived from GABAA receptor modulators. Proc Natl Acad Sci 104:8059-8064. https://doi.org/ 10.1073/pnas.0701321104

Ng HW, Leggett C, Sakkiah S et al (2018) Competitive docking model for prediction of the human nicotinic acetylcholine receptor $\alpha 7$ binding of tobacco constituents. Oncotarget 9:16899-16916. https://doi.org/10.18632/oncotarget.24458

O'Brien J, Wilson I, Orton T, Pognan F (2000) Investigation of the Alamar Blue (resazurin) fluorescent dye for the assessment of mammalian cell cytotoxicity. Eur J Biochem 267:5421-5426. https://doi.org/10.1046/j.1432-1327.2000.01606.x

Oh WC, Lutzu S, Castillo PE, Kwon H-B (2016) De novo synaptogenesis induced by GABA in the developing mouse cortex. Science 353:1037-1040. https://doi.org/10.1126/science.aaf5206

Oliveira EE, Schleicher S, Büschges A et al (2011) Desensitization of nicotinic acetylcholine receptors in central nervous system neurons of the stick insect (Carausius morosus) by imidacloprid and sulfoximine insecticides. Insect Biochem Mol Biol 41:872-880. https://doi.org/10.1016/j.ibmb.2011.08.001

Ooms J (2020) magick: advanced graphics and image-processing in R. R package version 2.3. https://CRAN.R-project.org/packa ge $=$ magick

European Food Safety Authority (EFSA) P, Medina-Pastor P, Triacchini G (2020) The 2018 European Union report on pesticide residues in food. EFSA J. https://doi.org/10.2903/j.efsa.2020. 6057

Palma E, Bertrand S, Binzoni T, Bertrand D (1996) Neuronal nicotinic alpha 7 receptor expressed in Xenopus oocytes presents five putative binding sites for methyllycaconitine. J Physiol 491:151-161. https://doi.org/10.1113/jphysiol.1996.sp021203

Papke RL, Porter Papke JK, Rose GM (2004) Activity of $\alpha 7$-selective agonists at nicotinic and serotonin 5HT3 receptors expressed in Xenopus oocytes. Bioorg Med Chem Lett 14:1849-1853. https:// doi.org/10.1016/j.bmcl.2003.09.104

Papke RL, Dwoskin LP, Crooks PA et al (2008) Extending the analysis of nicotinic receptor antagonists with the study of $\alpha 6$ nicotinic receptor subunit chimeras. Neuropharmacology 54:1189-1200. https://doi.org/10.1016/j.neuropharm.2008.03.010

Papke RL, Kem WR, Soti F et al (2009) Activation and desensitization of nicotinic $\alpha 7$-type acetylcholine receptors by benzylidene anabaseines and nicotine. J Pharmacol Exp Ther 329:791-807. https://doi.org/10.1124/jpet.108.150151

Papke RL, Trocmé-Thibierge C, Guendisch D et al (2011) Electrophysiological perspectives on the therapeutic use of nicotinic acetylcholine receptor partial agonists. J Pharmacol Exp Ther 337:367-379. https://doi.org/10.1124/jpet.110.177485

Paradiso KG, Steinbach JH (2003) Nicotine is highly effective at producing desensitization of rat $\alpha 4 \beta 2$ neuronal nicotinic receptors. J Physiol 553:857-871. https://doi.org/10.1113/jphysiol.2003. 053447

Peng X, Katz M, Gerzanich V et al (1994) Human alpha 7 acetylcholine receptor: cloning of the alpha 7 subunit from the SH-SY5Y cell line and determination of pharmacological properties of native receptors and functional alpha 7 homomers expressed in Xenopus oocytes. Mol Pharmacol 45:546-554

Puchacz E, Buisson B, Bertrand D, Lukas RJ (1994) Functional expression of nicotinic acetylcholine receptors containing rat $\alpha 7$ subunits in human SH-SY5Y neuroblastoma cells. FEBS Lett 354:155-159. https://doi.org/10.1016/0014-5793(94)01108-7 
Quick MW, Lester RAJ (2002) Desensitization of neuronal nicotinic receptors. J Neurobiol 53:457-478. https://doi.org/10.1002/neu. 10109

Quik M, Kulak JM (2002) Nicotine and nicotinic receptors; relevance to Parkinson's Disease. Neurotoxicology 23:581-594. https://doi. org/10.1016/S0161-813X(02)00036-0

Quik M, Wonnacott S (2011) $\alpha 6 \beta 2 *$ and $\alpha 4 \beta 2 *$ nicotinic acetylcholine receptors as drug targets for Parkinson's Disease. Pharmacol Rev 63:938-966. https://doi.org/10.1124/pr.110.003269

R Core Team (2020) R: A language and environment for statistical computing. R Foundation for Statistical Computing, Vienna, Austria. https://www.R-project.org

Rapier C, Lunt GG, Wonnacott S (1988) Stereoselective nicotineinduced release of dopamine from striatal synaptosomes: concentration dependence and repetitive stimulation. J Neurochem 50:1123-1130. https://doi.org/10.1111/j.1471-4159.1988.tb105 82. $\mathrm{x}$

Schrödinger Release 2020-2 (2020) Maestro. Schrödinger, LLC, New York

Rice D, Barone S Jr (2000) Critical periods of vulnerability for the developing nervous system: evidence from humans and animal models. Environ Health Perspect 108:511-533. https://doi.org/ 10.1289/ehp.00108s3511

Ring A, Strom BO, Turner SR et al (2015) Bispyridinium compounds inhibit both muscle and neuronal nicotinic acetylcholine receptors in human cell lines. PLoS ONE 10:e0135811. https://doi. org/10.1371/journal.pone.0135811

Ritz C, Baty F, Streibig JC, Gerhard D (2015) Dose-response analysis using R. PLoS ONE 10:e0146021. https://doi.org/10.1371/journ al.pone. 0146021

Rollema H, Hurst RS (2018) The contribution of agonist and antagonist activities of $\alpha 4 \beta 2 *$ nAChR ligands to smoking cessation efficacy: a quantitative analysis of literature data. Psychopharmacology 235:2479-2505. https://doi.org/10.1007/s00213-018-4921-9

Rollema H, Chambers LK, Coe JW et al (2007) Pharmacological profile of the $\alpha 4 \beta 2$ nicotinic acetylcholine receptor partial agonist varenicline, an effective smoking cessation aid. Neuropharmacology 52:985-994. https://doi.org/10.1016/j.neuropharm.2006. 10.016

Rollema H, Shrikhande A, Ward KM et al (2010) Pre-clinical properties of the $\alpha 4 \beta 2$ nicotinic acetylcholine receptor partial agonists varenicline, cytisine and dianicline translate to clinical efficacy for nicotine dependence. Br J Pharmacol 160:334-345. https:// doi.org/10.1111/j.1476-5381.2010.00682.x

Romoli B, Lozada AF, Sandoval IM et al (2019) Neonatal nicotine exposure primes midbrain neurons to a dopaminergic phenotype and increases adult drug consumption. Biol Psychiatry 86:344355. https://doi.org/10.1016/j.biopsych.2019.04.019

Rovida C, Barton-Maclaren T, Benfenati E et al (2020) Internationalization of read-across as a validated new approach method (NAM) for regulatory toxicology. ALTEX Altern Anim Exp 37:579-606. https://doi.org/10.14573/altex.1912181

Sakkiah S, Leggett C, Pan B et al (2020) Development of a nicotinic acetylcholine receptor $\mathrm{nAChR} \alpha 7$ binding activity prediction model. J Chem Inf Model 60:2396-2404. https://doi.org/10. 1021/acs.jcim.0c00139

Šantrůčková E, Doležal V, El-Fakahany EE, Jakubík J (2014) Longterm activation upon brief exposure to xanomleline is unique to M1 and M4 Subtypes of muscarinic acetylcholine receptors. PLoS ONE 9:e88910. https://doi.org/10.1371/journal.pone. 0088910

Schaefer TL, Grace CE, Braun AA et al (2013) Cognitive impairments from developmental exposure to serotonergic drugs: citalopram and MDMA. Int J Neuropsychopharmacol 16:1383-1394. https:// doi.org/10.1017/S1461145712001447
Schildknecht S, Karreman C, Pöltl D et al (2013) Generation of genetically-modified human differentiated cells for toxicological tests and the study of neurodegenerative diseases. ALTEX Altern Anim Exp 30:427-444. https://doi.org/10.14573/altex.2013.4. 427

Scholz D, Pöltl D, Genewsky A et al (2011) Rapid, complete and large-scale generation of post-mitotic neurons from the human LUHMES cell line. J Neurochem 119:957-971. https://doi.org/ 10.1111/j.1471-4159.2011.07255.x

Sherman W, Day T, Jacobson MP et al (2006) Novel procedure for modeling ligand/receptor induced fit effects. J Med Chem 49:534-553. https://doi.org/10.1021/jm050540c

Sirenko O, Parham F, Dea S et al (2019) Functional and mechanistic neurotoxicity profiling using human iPSC-derived neural 3D cultures. Toxicol Sci 167:58-76. https://doi.org/10.1093/toxsci/ kfy 218

Slikker W Jr, Xu ZA, Levin ED, Slotkin TA (2005) Mode of action: disruption of brain cell replication, second messenger, and neurotransmitter systems during development leading to cognitive dysfunction-developmental neurotoxicity of nicotine. Crit Rev Toxicol 35:703-711. https://doi.org/10.1080/104084405910074 21

Slotkin TA, Tate CA, Cousins MM, Seidler FJ (2006) Prenatal nicotine exposure alters the responses to subsequent nicotine administration and withdrawal in adolescence: serotonin receptors and cell signaling. Neuropsychopharmacology 31:2462-2475. https://doi. org/10.1038/sj.npp.1300988

Slotkin TA, Skavicus S, Card J et al (2016) Diverse neurotoxicants target the differentiation of embryonic neural stem cells into neuronal and glial phenotypes. Toxicology 372:42-51. https://doi. org/10.1016/j.tox.2016.10.015

Smirnova L, Hogberg HT, Leist M, Hartung T (2014) Developmental neurotoxicity - challenges in the 21st century and in vitro opportunities. ALTEX Altern Anim Exp 31:129-156. https://doi.org/ 10.14573/altex.1403271

Smirnova L, Harris G, Delp J et al (2016) A LUHMES 3D dopaminergic neuronal model for neurotoxicity testing allowing long-term exposure and cellular resilience analysis. Arch Toxicol 90:27252743. https://doi.org/10.1007/s00204-015-1637-z

Smith JC, Ballanyi K, Richter DW (1992) Whole-cell patch-clamp recordings from respiratory neurons in neonatal rat brainstem in vitro. Neurosci Lett 134:153-156. https://doi.org/10.1016/ 0304-3940(92)90504-Z

Song J, Zhong C, Bonaguidi MA et al (2012) Neuronal circuitry mechanism regulating adult quiescent neural stem-cell fate decision. Nature 489:150-154. https://doi.org/10.1038/nature11306

Stevens TR, Krueger SR, Fitzsimonds RM, Picciotto MR (2003) Neuroprotection by nicotine in mouse primary cortical cultures involves activation of calcineurin and L-type calcium channel inactivation. J Neurosci 23:10093-10099. https://doi.org/10. 1523/JNEUROSCI.23-31-10093.2003

Stiegler NV, Krug AK, Matt F, Leist M (2011) Assessment of chemical-induced impairment of human neurite outgrowth by multiparametric live cell imaging in high-density cultures. Toxicol Sci 121:73-87. https://doi.org/10.1093/toxsci/kfr034

Tan J, Galligan JJ, Hollingworth RM (2007) Agonist actions of neonicotinoids on nicotinic acetylcholine receptors expressed by cockroach neurons. Neurotoxicology 28:829-842. https://doi. org/10.1016/j.neuro.2007.04.002

Thompson DA, Lehmler H-J, Kolpin DW et al (2020) A critical review on the potential impacts of neonicotinoid insecticide use: current knowledge of environmental fate, toxicity, and implications for human health. Environ Sci Process Impacts. https://doi.org/10. 1039/C9EM00586B

Tomizawa M, Casida JE (1999) Minor structural changes in nicotinoid insecticides confer differential subtype selectivity for mammalian 
nicotinic acetylcholine receptors. Br J Pharmacol 127:115-122. https://doi.org/10.1038/sj.bjp.0702526

Tomizawa M, Casida JE (2000) Imidacloprid, thiacloprid, and their imine derivatives up-regulate the $\alpha 4 \beta 2$ nicotinic acetylcholine receptor in M10 cells. Toxicol Appl Pharmacol 169:114-120. https://doi.org/10.1006/taap.2000.9057

Tomizawa M, Casida JE (2003) Selective toxicity of neonicotinoids attributable to specificity of insect and mammalian nicotinic receptors. Annu Rev Entomol 48:339-364. https://doi.org/10. 1146/annurev.ento.48.091801.112731

Tomizawa M, Casida JE (2005) NEONICOTINOID INSECTICIDE TOXICOLOGY: mechanisms of selective action. Annu Rev Pharmacol Toxicol 45:247-268. https://doi.org/10.1146/annur ev.pharmtox.45.120403.095930

Tomizawa M, Lee DL, Casida JE (2000) Neonicotinoid insecticides: molecular features conferring selectivity for insect versus mammalian nicotinic receptors. J Agric Food Chem 48:6016-6024. https://doi.org/10.1021/jf000873c

Tomizawa M, Maltby D, Talley TT et al (2008) Atypical nicotinic agonist bound conformations conferring subtype selectivity. Proc Natl Acad Sci 105:1728-1732. https://doi.org/10.1073/ pnas.0711724105

Tong Z-B, Hogberg H, Kuo D et al (2017) Characterization of three human cell line models for high-throughput neuronal cytotoxicity screening: neurotoxicity models. J Appl Toxicol 37:167-180. https://doi.org/10.1002/jat.3334

Tozuka Y, Fukuda S, Namba T et al (2005) GABAergic excitation promotes neuronal differentiation in adult hippocampal progenitor cells. Neuron 47:803-815. https://doi.org/10.1016/j.neuron. 2005.08.023

Trestle Technology, LLC (2017) shinyTree: jsTree Bindings for Shiny. $\mathrm{R}$ package version 0.2.5.

Vaidyanathan R, Xie Y, Allaire J, et al (2019) htmlwidgets: HTML Widgets for R. R package version 1.5.1. https://CRAN.R-proje ct.org/package $=$ htmlwidgets

Wagner GP, Kin K, Lynch VJ (2012) Measurement of mRNA abundance using RNA-seq data: RPKM measure is inconsistent among samples. Theory Biosci 131:281-285. https://doi.org/ 10.1007/s12064-012-0162-3

Walsh RM, Roh S-H, Gharpure A et al (2018) Structural principles of distinct assemblies of the human $\alpha 4 \beta 2$ nicotinic receptor. Nature 557:261-265. https://doi.org/10.1038/s41586-018-0081-7

Welsby P, Rowan M, Anwyl R (2006) Nicotinic receptor-mediated enhancement of long-term potentiation involves activation of metabotropic glutamate receptors and ryanodine-sensitive calcium stores in the dentate gyrus. Eur J Neurosci 24:3109-3118. https://doi.org/10.1111/j.1460-9568.2006.05187.x

Wheeler DG, Cooper E (2004) Weak synaptic activity induces ongoing signaling to the nucleus that is enhanced by BDNF and suppressed by low-levels of nicotine. Mol Cell Neurosci 26:50-62. https://doi.org/10.1016/j.mcn.2003.12.016

Wickham H (2016) ggplot2: elegant graphics for data analysis. Springer, New York

Wickham H (2020) modelr: Modelling Functions that Work with the Pipe. R package version 0.1.6. https://CRAN.R-project.org/packa ge $=$ modelr

Wickham H, Averick M, Bryan J et al (2019) Welcome to the tidyverse. J Open Source Softw 4:1686. https://doi.org/10.21105/joss. 01686
Wickham H, François R, Henry L, Müller K (2020) dplyr: a grammar of data manipulation. $\mathrm{R}$ package version 0.8.5. https://CRAN.Rproject.org/package $=$ dplyr

Wildman SA, Crippen GM (1999) Prediction of physicochemical parameters by atomic contributions. J Chem Inf Comput Sci 39:868-873. https://doi.org/10.1021/ci9903071

Wilke CO (2019) cowplot: streamlined plot theme and plot annotations for "ggplot2". R package version 1.0.0. https://CRAN.R-project. org/package $=$ cowplot

Williams DK, Wang J, Papke RL (2011) Investigation of the molecular mechanism of the $\alpha 7$ nicotinic acetylcholine receptor positive allosteric modulator PNU-120596 provides evidence for two distinct desensitized states. Mol Pharmacol 80:1013-1032. https:// doi.org/10.1124/mol.111.074302

Witt B, Meyer S, Ebert F et al (2017) Toxicity of two classes of arsenolipids and their water-soluble metabolites in human differentiated neurons. Arch Toxicol 91:3121-3134. https://doi.org/10.1007/ s00204-017-1933-X

Wu J, Liu Q, Yu K et al (2006) Roles of nicotinic acetylcholine receptor $\beta$ subunits in function of human $\alpha 4$-containing nicotinic receptors. J Physiol 576:103-118. https://doi.org/10.1113/jphysiol. 2006.114645

Wu X, Fu Y, Knott G et al (2012) GABA signaling promotes synapse elimination and axon pruning in developing cortical inhibitory interneurons. J Neurosci 32:331-343. https://doi.org/10.1523/ JNEUROSCI.3189-11.2012

Yamamoto I, Tomizawa M, Saito T et al (1998) Structural factors contributing to insecticidal and selective actions of neonicotinoids. Arch Insect Biochem Physiol 37:24-32. https://doi.org/ 10.1002/(SICI)1520-6327(1998)37:1\%3c24::AID-ARCH4\% 3e3.0.CO;2-V

Young MD, Wakefield MJ, Smyth GK, Oshlack A (2010) Gene ontology analysis for RNA-seq: accounting for selection bias. Genome Biol 11:R14. https://doi.org/10.1186/gb-2010-11-2-r14

Zahedi A, Phandthong R, Chaili A et al (2019) Mitochondrial stress response in neural stem cells exposed to electronic cigarettes. iScience 16:250-269. https://doi.org/10.1016/j.isci.2019.05.034

Zhang X, Yin M, Zhang M (2014) Cell-based assays for Parkinson's disease using differentiated human LUHMES cells. Acta Pharmacol Sin 35:945-956. https://doi.org/10.1038/aps.2014.36

Zhang T, Song S, Bai X et al (2019) A nationwide survey of urinary concentrations of neonicotinoid insecticides in China. Environ Int 132:105114. https://doi.org/10.1016/j.envint.2019.105114

Ziviani E, Lippi G, Bano D et al (2011) Ryanodine receptor-2 upregulation and nicotine-mediated plasticity. EMBO J 30:194-204. https://doi.org/10.1038/emboj.2010.279

Zoli M, Pistillo F, Gotti C (2015) Diversity of native nicotinic receptor subtypes in mammalian brain. Neuropharmacology 96:302-311. https://doi.org/10.1016/j.neuropharm.2014.11.003

Publisher's Note Springer Nature remains neutral with regard to jurisdictional claims in published maps and institutional affiliations. 